\title{
Enhancing the Gas Separation Selectivity of Mixed-Matrix Membranes Using a Dual-Interfacial Engineering Approach
}

Chunhui Wu, Kexin Zhang, Hongliang Wang, Yaqi Fan, Songwei Zhang, Sanfeng He, Fang Wang, Yu Tao, Xiaowen Zhao, Yue-Biao Zhang, Yanhang Ma, Yongjin Lee, Tao Li*

School of Physical Science and Technology, ShanghaiTech University, Shanghai, China 201210

\section{Section S1. Materials}

Nickel (II) nitrate hexahydrate $\left(\mathrm{Ni}\left(\mathrm{NO}_{3}\right)_{2} \cdot 6 \mathrm{H}_{2} \mathrm{O}\right.$, Greagent, 98.5\%), cobalt (II) nitrate hexahydrate $\left(\mathrm{Co}\left(\mathrm{NO}_{3}\right)_{2} \cdot 6 \mathrm{H}_{2} \mathrm{O}\right.$, SCRC, 98.5\%), zirconium(IV) chloride ( $\mathrm{ZrCl}_{4}$, Alfa Aesar, 98\%), zirconyl chloride octahydrate $\left(\mathrm{ZrOCl}_{2} \cdot 8 \mathrm{H}_{2} \mathrm{O}\right.$, Greagent, 98\%), titanium(IV) isopropoxide (Alfa Aesar, 98\%), nickel (II) acetate tetrahydrate (Ni(OAC) $2 \cdot 4 \mathrm{H}_{2} \mathrm{O}$, J\&K, 99\%), iron(III) chloride hexahydrate $\left(\mathrm{FeCl}_{3} \cdot 6 \mathrm{H}_{2} \mathrm{O}\right.$, Aladdin, 99\%), chromic(III) nitrate nonahydrate $\left(\mathrm{Cr}\left(\mathrm{NO}_{3}\right) \cdot 9 \mathrm{H}_{2} \mathrm{O}\right.$, Aladdin, 99\%), 2,5-dihydroxyterephthalic acid (DOT, Tokyo Chemical Industry, 98\%), 2aminoterephthalic acid ( $\mathrm{NH}_{2}$-BDC, Tokyo Chemical Industry, 98\%), 1,4-dicarboxybenzene ( $\mathrm{H}_{2} \mathrm{BDC}$, Aladdin, 99\%), fumaric acid (FA, J\&K, 98\%), 1,3,5-benzenetricarboxylic acid ( $\mathrm{H}_{3} \mathrm{BTC}$, Alfa Aesar, 98\%), benzoic acid (BA, Aladdin, 99.5\%), acetic anhydride ( $\mathrm{Ac}_{2} \mathrm{O}, \mathrm{SCRC}, 98.5 \%$ ), triethylamine (TEA, Aladdin, 99\%), acetic acid glacial (HOAC, Greagent, 99.5\%), formic acid 
(HCOOH, Alfa Aesar, 98\%), hydrofluoric acid (HF, Aladdin, 40\%), nitric acid $\left(\mathrm{HNO}_{3}\right.$, SCRC, $65.0 \sim 68.0 \%$ ), sodium hydroxide ( $\mathrm{NaOH}$, Aladdin, 96\%), N,N-dimethylformamide (DMF, Greagent, 99.5\%), chloroform $\left(\mathrm{CHCl}_{3}\right.$, Greagent, 99\%), ethanol (Greagent, 99.7\%), tetrahydrofuran (THF, SCRC, 99\%), 1-methyl-2-pyrrolidinone (NMP, Aladdin, 99\%), and anhydrous methanol (Greagent, 99.5\%) were purchased from the mentioned sources and used without further purification. 4,4'-Oxydiphthalic anhydride (ODPA, Aladdin, 97\%) and 4,4'(hexafluoroisopropylidene) diphthalic anhydride (6FDA, Tokyo Chemical Industry were purified by recrystallization in acetic anhydride. 2,4,6-trimethyl-1,3-phenylenediamine (DAM, Adamas, 98\%) and 2,3,5,6-tetramethyl-1,4-phenylenediamine (durene, Tokyo Chemical Industry, 98\%) were purified by recrystallization in ethanol. 


\section{Section S2. Synthesis}

\section{Synthesis of 6FDA-durene}

Durene (2.354 g,14.33 mmol) and NMP (26 mL) were added into a $250 \mathrm{~mL}$ flask equipped with a nitrogen inlet. The mixture was cooled to $0{ }^{\circ} \mathrm{C}$ and then 6FDA (6.364 g, $\left.14.33 \mathrm{mmol}\right)$ and NMP (26 mL) were added. The solution was stirred for 24 hours to form polyamic acid. Next, 2 $\mathrm{mL}$ of TEA, $5.4 \mathrm{~mL}$ of $\mathrm{Ac}_{2} \mathrm{O}$ and NMP $(10 \mathrm{~mL})$ were added. The mixture was vigorously stirred for 20 hours to allow complete imidization. The polyimide product was precipitated in methanol (1 L), filtered, washed with methanol several times and dried under vacuum at $150{ }^{\circ} \mathrm{C}$ for 24 hours.

\section{Synthesis of ODPA-DAM/6FDA-DAM}

ODPA-DAM/6FDA-DAM was obtained following a previous method. ${ }^{1} 2.152 \mathrm{~g}$ (14.33mmol) DAM was dissolved in $15 \mathrm{~mL}$ NMP under a nitrogen atmosphere. Then, the reaction vessels were immersed in an ice-bath. 4.445/6.364 g (14.33mmol) ODPA/6FDA and additional 15 mL NMP was added into the reaction solution. Then the mixture was stirred for 24 hours to form a viscous poly (amic acid) (PAA) solution. For the imidization, a solution of $2 \mathrm{~mL}$ triethylamine (TEA) and $5.4 \mathrm{~mL}$ of $\mathrm{Ac}_{2} \mathrm{O}$ dissolved in $6 \mathrm{~mL}$ NMP was added. The mixture was stirred at room temperature for another 24 hours. The obtained mixture was added slowly into methanol to obtain white polyimide fibers. The as-synthesized polyimide was washed several times by anhydrous methanol before drying in a vacuum oven at $150{ }^{\circ} \mathrm{C}$ for $24 \mathrm{~h}$. 


\section{Synthesis of MOF-801}

MOF-801 was synthesized by dissolving $\mathrm{ZrCl}_{4}$ (1.398 g, $6 \mathrm{mmol}$ ) and fumaric acid (696.4 mg, $6 \mathrm{mmol}$ ) in $200 \mathrm{~mL}$ DMF. After mixing, $13.8 \mathrm{~mL}$ acetic acid and $0.6 \mathrm{~mL}$ triethylamine were added. The mixture was heated in an oven at $85^{\circ} \mathrm{C}$ for 24 hours. After cooling down to room temperature, the product was collected by centrifugation and washed by fresh DMF and anhydrous methanol three times respectively.

\section{Synthesis of MOF-801(Large size)}

Large size MOF-801 was synthesized according to the method of Yaghi et al. ${ }^{2}$ MOF801(Large size) was synthesized by dissolving $\mathrm{ZrOCl}_{2} \cdot 8 \mathrm{H}_{2} \mathrm{O}(0.23 \mathrm{~g}, 0.70 \mathrm{mmol})$ and fumaric acid (0.081 g, $0.70 \mathrm{mmol})$ in $35 \mathrm{~mL}$ DMF. After mixing, $5.3 \mathrm{~mL}$ formic acid and was added. The mixture was heated in an oven at $120{ }^{\circ} \mathrm{C}$ for 20 hours. After cooling down to room temperature, the product was collected by centrifugation and washed by fresh DMF and anhydrous methanol three times respectively.

\section{Synthesis of UiO-66}

UiO-66 was synthesized by dissolving $\mathrm{ZrCl}_{4}$ (583.6 mg, $2.5 \mathrm{mmol}$ ) and $\mathrm{H}_{2} \mathrm{BDC}$ (413.6 mg, 3.56 mmol) in $100 \mathrm{~mL}$ DMF and $1 \mathrm{~mL}$ ethanol. After mixing, $9.14 \mathrm{~mL}$ acetic acid was added. The mixture was heated in an oven at $120{ }^{\circ} \mathrm{C}$ for 20 hours. After cooling down to room temperature, 
the product was collected by centrifugation and washed by fresh DMF and anhydrous methanol three times respectively.

\section{Synthesis of UiO-66-NH2}

UiO-66- $\mathrm{NH}_{2}$ was synthesized by dissolving $\mathrm{ZrCl}_{4}$ (242.4 mg, $\left.1.04 \mathrm{mmol}\right)$ and $\mathrm{NH}_{2}-\mathrm{BDC}$ (188 mg, $1.04 \mathrm{mmol}$ ) in $60 \mathrm{~mL}$ DMF. After mixing, $1.8 \mathrm{~mL}$ acetic acid was added. The mixture was heated in an oven at $120^{\circ} \mathrm{C}$ for 20 hours. After cooling down to room temperature, the product was collected by centrifugation and washed by fresh DMF and anhydrous methanol three times respectively.

\section{Synthesis of MIL-101(Cr)}

MIL-101(Cr) was synthesized by dissolving $\mathrm{Cr}\left(\mathrm{NO}_{3}\right) \cdot 9 \mathrm{H}_{2} \mathrm{O}(1 \mathrm{~g}, 2.5 \mathrm{mmol})$ and $\mathrm{H}_{2} \mathrm{BDC}$ (415 mg, $2.5 \mathrm{mmol}$ ) in $10 \mathrm{~mL}$ deionized water respectively. After mixing, the prepared solution was transferred to $50 \mathrm{~mL}$ hydrothermal reactor. The mixture was heated in an oven at $200{ }^{\circ} \mathrm{C}$ for 10 hours. After cooling down to room temperature, the product was collected by centrifugation and washed by fresh DMF and anhydrous methanol three times respectively.

\section{Synthesis of Ni-MOF-74 (polycrystalline nanoparticles)}

A mixture of $2.75 \mathrm{~mL}$ DMF, $2.75 \mathrm{~mL}$ ethanol and $1.8 \mathrm{~mL}$ deionized water containing $1.8 \mathrm{mmol}$ $\mathrm{Ni}\left(\mathrm{NO}_{3}\right)_{2} \cdot 6 \mathrm{H}_{2} \mathrm{O}(523.4 \mathrm{mg})$ and $0.2 \mathrm{mmol}$ DOT (39.63 mg ) was stirred at $500 \mathrm{rpm}$ for 5 minutes. After mixing, $57 \mu \mathrm{L}$ acetic acid was added. Then, $1.5 \mathrm{~mL} 1 \mathrm{M} \mathrm{NaOH}$ aqueous $(1.5 \mathrm{mmol})$ was 
added to the mixture with stirring (600 rpm). The prepared solution was transferred to $20 \mathrm{~mL}$ reaction vessels. Then, the reaction vessel was fixed in the microwave reactor (Biotage Initiator+) and reacted at $100{ }^{\circ} \mathrm{C}$ for $90 \mathrm{~min}$ with stirring $(600 \mathrm{rpm})$. After the reaction, the as-synthesized materials were washed with DMF and anhydrous methanol for three times.

\section{Synthesis of Ni-MOF-74 (Large size)}

The solution for Ni-MOF-74 was prepared by dissolving a mixture of $\mathrm{Ni}(\mathrm{OAC})_{2} \cdot 4 \mathrm{H}_{2} \mathrm{O}(746.52$ mg, $3 \mathrm{mmol}$ ) and DOT (594.39 mg, $3 \mathrm{mmol}$ ) under sonication in a 1:1 (v/v) mixture of THF (30 $\mathrm{mL})$ and deionized water $(30 \mathrm{~mL})$. The prepared solution was transferred to $100 \mathrm{~mL}$ reaction vessels and heated to $110{ }^{\circ} \mathrm{C}$ in an oil bath for $6 \mathrm{~h}$ with magnetic stirring (600 rpm). After the reaction, the as-synthesized materials were washed with DMF and anhydrous methanol for three times.

Synthesis of MOF-801@Ni-MOF-74/UiO-66@Ni-MOF-74/UiO-66-NH2@Ni-MOF-74/MIL101(Cr)@Ni-MOF-74

A mixture of $2.75 \mathrm{~mL}$ DMF, $2.75 \mathrm{~mL}$ ethanol and $1.8 \mathrm{~mL}$ deionized water containing $1.8 \mathrm{mmol}$ $\mathrm{Ni}\left(\mathrm{NO}_{3}\right)_{2} \cdot 6 \mathrm{H}_{2} \mathrm{O}(523.4 \mathrm{mg}$ ) and $0.2 \mathrm{mmol} \mathrm{DOT}$ (39.63 mg ) was stirred at $500 \mathrm{rpm}$ for 5 minutes, followed by dispersion of 120 mg as-synthesized MOF-801/ UiO-66/ UiO-66-NH2/MIL-101(Cr) under sonication. After mixing, $57 \mu \mathrm{L}$ acetic acid was added. Then, $1.5 \mathrm{~mL} 1 \mathrm{M} \mathrm{NaOH}$ aqueous (1.5 mmol) was added to the mixture with stirring (600 rpm). The prepared solution was transferred to $20 \mathrm{~mL}$ reaction vessels. Then, the reaction vessel was fixed in the microwave reactor 
(Biotage Initiator + ) and reacted at $100{ }^{\circ} \mathrm{C}$ for $90 \mathrm{~min}$ with stirring $(600 \mathrm{rpm})$. After the reaction, the as-synthesized materials were washed with DMF and anhydrous methanol for three times.

\section{Synthesis of UiO-66@Co-MOF-74}

A mixture of $1.6 \mathrm{~mL}$ DMF and $1.6 \mathrm{~mL}$ ethanol containing $1.8 \mathrm{mmol} \mathrm{Co}\left(\mathrm{NO}_{3}\right)_{2} \cdot 6 \mathrm{H}_{2} \mathrm{O}(523.9$ $\mathrm{mg}$ ) and $0.2 \mathrm{mmol}$ DOT (39.63 mg ) was stirred at $500 \mathrm{rpm}$ for 5 minutes, followed by dispersion of $60 \mathrm{mg}$ as-synthesized $\mathrm{UiO}-66$ under sonication. After mixing, $57 \mu \mathrm{L}$ acetic acid was added. Then, $1.5 \mathrm{~mL} \mathrm{1M} \mathrm{NaOH}$ aqueous $(1.5 \mathrm{mmol})$ was added to the mixture with stirring (600 rpm). The prepared solution was transferred to $20 \mathrm{~mL}$ reaction vessels. Then, the reaction vessel was fixed in the microwave reactor (Biotage Initiator+) and reacted at $100{ }^{\circ} \mathrm{C}$ for 90 min with stirring (600 rpm). After the reaction, the as-synthesized materials were washed with DMF and anhydrous methanol for three times.

\section{Synthesis of MOF-801@UiO-66}

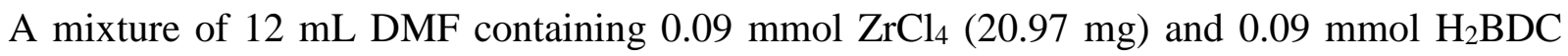
(14.95 mg) was stirred at $500 \mathrm{rpm}$ for 5 minutes, followed by dispersion of $25 \mathrm{mg}$ as-synthesized MOF-801 under sonication. After mixing, $2.7 \mathrm{mmol}$ benzoic acid (329.7 $\mathrm{mg}$ ) was added. The prepared solution was transferred to $5 \mathrm{~mL}$ reaction vessels. Then, the reaction vessel was fixed in the microwave reactor (Biotage Initiator+) and reacted at $120^{\circ} \mathrm{C}$ for 30 min with stirring (600 rpm). After the reaction, the as-synthesized materials were washed with DMF and anhydrous methanol for three times. 


\section{Synthesis of UiO-66@MOF-801}

A mixture of $2.19 \mathrm{~mL}$ DMF containing $0.219 \mathrm{mmol} \mathrm{ZrOCl}_{2} \cdot 8 \mathrm{H}_{2} \mathrm{O}(70.6 \mathrm{mg})$ and $0.219 \mathrm{mmol}$ fumaric acid (25.4 mg) was stirred at 500 rpm for 5 minutes, followed by dispersion of $15 \mathrm{mg}$ assynthesized UiO-66 under sonication. After mixing, $1.002 \mathrm{~mL}$ acetic acid was added. The prepared solution was transferred to $5 \mathrm{~mL}$ reaction vessels. Then, the reaction vessel was fixed in the microwave reactor (Biotage Initiator+) and reacted at $120^{\circ} \mathrm{C}$ for 60 min with stirring (600 rpm). After the reaction, the as-synthesized materials were washed with DMF and anhydrous methanol for three times.

\section{Synthesis of UiO-66@MIL-125(Ti)}

A mixture of $3.49 \mathrm{~mL} \mathrm{DMF}$ and $0.387 \mathrm{~mL}$ anhydrous methanol containing $0.5 \mathrm{mmol}$ titanium(IV) isopropoxide (142.1 mg) and $0.775 \mathrm{mmol} \mathrm{H}_{2} \mathrm{BDC}(128.8 \mathrm{mg}$ ) was stirred at $500 \mathrm{rpm}$ for 5 minutes, followed by dispersion of $90 \mathrm{mg}$ as-synthesized UiO-66 under sonication. The prepared solution was transferred to $5 \mathrm{~mL}$ reaction vessels. Then, the reaction vessel was fixed in the microwave reactor (Biotage Initiator+) and reacted at $150{ }^{\circ} \mathrm{C}$ for 90 min with stirring (600 rpm). After the reaction, the as-synthesized materials were washed with DMF and anhydrous methanol for three times. 


\section{Synthesis of UiO-66@MIL-100(Fe)}

A mixture of $6 \mathrm{~mL}$ deionized water containing $0.6 \mathrm{mmol} \mathrm{FeCl}_{3} \cdot 6 \mathrm{H}_{2} \mathrm{O}(162.2 \mathrm{mg})$ and 0.266 mmol $\mathrm{H}_{3} \mathrm{BTC}$ (55.9 mg) was stirred at $500 \mathrm{rpm}$ for 5 minutes, followed by dispersion of $20 \mathrm{mg}$ as-synthesized UiO-66 under sonication. The prepared solution was transferred to $20 \mathrm{~mL}$ reaction vessels. Then, the reaction vessel was fixed in the microwave reactor (Biotage Initiator+) and reacted at $130{ }^{\circ} \mathrm{C}$ for 8 min with stirring (600 rpm). After the reaction, the as-synthesized materials were washed with DMF and anhydrous methanol for three times.

\section{Synthesis of MOF-801@6FDA-durene/801@Ni74@6FDA-durene}

7 mg as-synthesized MOF-801/MOF-801@Ni-MOF-74 was re-dispersed in 1 mL $\mathrm{CHCl}_{3}$. Then, $1.4 \mathrm{~mL} 10 \mathrm{mg} / \mathrm{mL}$ 6FDA-durene $\mathrm{CHCl}_{3}$ solution was added. Next, the solutions were sonicated by a probe sonicator for $1 \mathrm{~min}$ and then the solution was stirred (500 rpm) at room temperature for 30 minutes. The sample was obtained by centrifugation, Then the sample was re-dispersed in $1 \mathrm{~mL} \mathrm{CHCl}_{3}$ with sonication. After sonicating $10 \mathrm{~min}$, the sample was obtained by centrifugation again. Finally, repeat this step twice.

\section{Membrane preparation}

To prepare neat ODPA-DAM/6FDA-DAM/6FDA-durene membrane, $5 \mathrm{wt} \%$ polymer in dry $\mathrm{CHCl}_{3}$ solution was filtered through a $0.45 \mathrm{~mm}$ PTFE filter onto a casting tray. The tray consisted 
of a glass ring attached to a leveled glass plate by epoxy sealant. After slow evaporation of solvent, the membranes were peeled off from the glass plate and dried overnight to remove residual solvent.

To fabricate mixed-matrix membranes (MMMs), MOF particles were centrifuged from $\mathrm{CHCl}_{3}$ and then mixed with a $5 \mathrm{wt} \%$ polymer/ $\mathrm{CHCl}_{3}$ solution. The solutions were sonicated by a probe sonicator for $1 \mathrm{~min}$ before casting a flat quartz plate. After slow evaporation of solvents, membranes were peeled off from the quartz plate and dried overnight.

\section{Section S3. Characterization}

Transmission electron microscope (TEM) images were acquired on a JEM 1400 field-emission transmission electron microscope with voltage set at $120 \mathrm{kV}$. High resolution transmission electron microscope (HRTEM) images were acquired on a JEM-2100 Plus field-emission transmission electron microscope with voltage set at $200 \mathrm{kV}$. Scanning electron microscope (SEM) images were acquired on a JEOL JSM 7800F Prime SEM. Energy-dispersive X-ray spectroscopy (EDS) elemental mapping images and line scan were collected on a JEM 1400 plus (120 kV). Powder X-ray diffraction patterns (PXRD) were acquired on a Bruker D8 Advance diffractometer with $\mathrm{Cu} \mathrm{Ka}$ radiation. TGA experiments were performed on a PerkinElmer TGA 8000. Samples were firstly heated to $150{ }^{\circ} \mathrm{C}$ and retained at that temperature for 30 minutes under $\mathrm{N}_{2}$ atmosphere to remove residual solvent and then heated to $700{ }^{\circ} \mathrm{C}$ at a rate of $20^{\circ} \mathrm{C} / \mathrm{min}$ under oxygen $\left(\mathrm{O}_{2}\right)$ atmosphere, and then kept $700{ }^{\circ} \mathrm{C}$ for $10 \mathrm{~min}$, and finally raised the temperature to $750{ }^{\circ} \mathrm{C}$ with rate of $20^{\circ} \mathrm{C} / \mathrm{min}$ at $\mathrm{O}_{2}$. Gas adsorption analysis was performed on Quantachrome Autosorb-iQ- 
MP volumetric gas adsorption analyzer. High-pressure adsorption isotherms were measured on a PCT Pro instruments from Setaram. For ultramicrotomy, samples need to be embedded into epoxy resin (EPON 812 , Sigma Aldrich) and cured at $60{ }^{\circ} \mathrm{C}$ for 24 hours. Ultrathin slices with thickness of $80 \mathrm{~nm}$ was cut by a Leica EM UC7 ultramicrotome.

\section{Gas adsorption kinetic measurement}

The $\mathrm{C}_{2} \mathrm{H}_{6}$ and $\mathrm{C}_{2} \mathrm{H}_{4}$ adsorption kinetic of MOF-801 and Ni-MOF-74 were studied by the pressure decay method using the vector dosing mode of Quantachrome Autosorb-iQ-MP volumetric gas adsorption analyzer. The illustration of the pressure decay adsorption apparatus employed for $\mathrm{C}_{2} \mathrm{H}_{6}$ and $\mathrm{C}_{2} \mathrm{H}_{4}$ adsorption kinetic measurements was show in Figure S15. The system includes: a manifold which had a known geometric volume $\left(\mathrm{V}_{\mathrm{m}}\right)$; a sample cell which contains the solid sample and is connected to the manifold via the valve 4; $\mathrm{He}$ and $\mathrm{C}_{2} \mathrm{H}_{6} \mathrm{C}_{2} \mathrm{H}_{4}$ gas inlet were connected to the manifold via valve 1 and 2; the system can be pumped by valve 3; the pressure can be recorded by the pressure transducer. For each measurement, $60 \mathrm{mg}$ MOF-801/NiMOF-74 powder which had been activated at $120^{\circ} \mathrm{C}$ under vacuum for $24 \mathrm{~h}$ was added in a $9 \mathrm{~mm}$ outer diameter sample cell and installed on the sample station. The sample cell which contained samples portion was placed in a constant temperature $\left(35^{\circ} \mathrm{C}\right)$ water bath. First, dosing helium to measure the dead volume $\left(\mathrm{V}_{\mathrm{d}}\right)$. Then, keeping the manifold and sample cell vacuumed. Second, the fixed dose of $\mathrm{C}_{2} \mathrm{H}_{6}$ or $\mathrm{C}_{2} \mathrm{H}_{4}$ was introduced into the manifold controlled by a computer with the valve 2 opened. If the target pressure was achieved, the valve 2 was been closed. The pressure 
transducer will read and record the pressure after it reached thermal equilibrium. Third, the $\mathrm{C}_{2} \mathrm{H}_{6}$ or $\mathrm{C}_{2} \mathrm{H}_{4}$ expanded into sample cell by open valve 4 , the pressure decay (which is a result of adsorption by the sample and the expansion of dead volume) was monitored by the pressure transducer as time change. The initial data points (typically $2 \sim 5$ seconds) after open the valve were not used to plot the experimental uptake curve since they were influenced by response of the pressure transducer as well as rapid expansion to dead volume expansion. In order to obtain the entire $\mathrm{C}_{2} \mathrm{H}_{6}$ and $\mathrm{C}_{2} \mathrm{H}_{4}$ adsorption kinetic curve, the pressure of sample cell and manifold right after opening the valve $4(t=0)$ was calculated by mass balance using the manifold pressure (before opening the valve 4) and manifold volume $\mathrm{V}_{\mathrm{m}}$ and dead volume $\mathrm{V}_{\mathrm{d}}$. We further use the constant surface concentration model, also known as the Fickian diffusion model, to fit the kinetic $\mathrm{C}_{2} \mathrm{H}_{6}$ and $\mathrm{C}_{2} \mathrm{H}_{4}$ uptake curves and calculate the value of $\mathrm{D}_{s} / \mathrm{r}^{2}$ (where $\mathrm{D}_{\mathrm{s}}$ is the diffusion coefficient and $r$ is the diffusion length) which determines the characteristic rate of mass uptake, the form of Fickian diffusion model is ${ }^{3}$ :

$$
\frac{M_{t}}{M_{\infty}}=1-\frac{6}{\pi^{2}} \exp \left(-\frac{n^{2} \pi^{2} D_{s} t}{r^{2}}\right)
$$

where $M_{t}(\mathrm{mmol})$ and $M_{\infty}(\mathrm{mmol})$ are moles adsorbed during time $t$ and as $t \rightarrow \infty, D_{s}\left(\mathrm{~m}^{2} / \mathrm{s}\right)$ is the diffusion coefficient, $r(\mathrm{~m})$ is the diffusion length. 
Molecular dynamics simulation of chemical interactions between the Ni-MOF-74 and 6FDAdurene

\section{MOF-74 modeling}

To construct simulation cells, firstly, we first prepared a slab model of Ni-MOF-74. Ni-MOF74 unit cell was cleaved on (100) facet in the x direction. The unsaturated metal ions in the unit cell were terminated by hydroxyl groups or water molecules. The modified unit cell (Figure S9) was expanded with $1 \times 8 \times 29$ to construct a MOF slab.

\section{FDA-durene modeling}

6FDA-durene (Figure S10) with 10 repeating unit was initially constructed by python package stk $^{4}$ and simply optimized using $\mathrm{MMFF}^{5}$.

\section{System modeling}

The system box (Figure S11) were initialized using PACKMOL ${ }^{6}$ with MOF-74 slab and 40 6FDA-durene. The size of the simulation box is $50 \mathrm{~nm} \times 20.90879 \mathrm{~nm} \times 20.1318 \mathrm{~nm}$.

\section{Simulation details}

Forcefield parameters for polymers and MOF-74 were employed from the consistent-valence forcefield ${ }^{7}$. MOF-74 was treated as a rigid framework. Atomic charges were obtained using the Rappe-Goddard charge equilibration method (QEq) ${ }^{8}$. In our calculations, the van der Waals and Coulombic interactions were subject to a $12 \AA$ cutoff. All MD procedures are performed using the LAMMPS ${ }^{9}$ (Large-scale Atomic/ Molecular Massively Parallel Simulator) software.

To obtain an equilibrated configuration of the composite system, we firstly performed $10 \mathrm{ps}$ 
relaxation procedures under additional force along x axis at $350 \mathrm{~K}$ under NVT ensemble. After that, a two-step MD simulation at different temperatures 1) NVT at $500 \mathrm{~K}$ and 2) NVT at 350K were performed. These processes were repeated twice. Each MD step ran over 1.5 ns with a timestep of 1 fs. Next, 10 ns MD trajectories obtained using NVT ensemble at $350 \mathrm{~K}$ were used for analysis.

\section{Analysis}

Here we identified atomic pairs of coordination bonds and hydrogen bonds that have a distance less than 3 and 2.5 angstroms, respectively. Figure S12a and b show the distributions of four atomic pairs within 3 or 2.5 angstrom among Ni-MOF-74 (partial and full activation) and polymers.

\section{Estimating diffusion coefficient of ethane and ethene in MOF-801 using molecular dynamics}

To estimate diffusion coefficients using molecular dynamics (MD), firstly, we constructed simulation cells. A unit cell of MOF-801 was adopted from Furukawa et al.’s work ${ }^{2}$ and expanded by $2 \times 2 \times 2$ to prepare the supercell. Then, an initial configuration of gas molecules in MOF801 was prepared by performing the grand canonical Monte Carlo simulation (GCMC) implemented in RASPA $2.0^{10}$. During the GCMC simulations, the MOF-801 frameworks were regarded as rigid. The long-range Coulomb interactions were handled with an Ewald summation technique. The van der Waals interactions for MOF-801 were described using a Lennard-Jones (LJ) potential with parameters from the universal force field (UFF) ${ }^{11}$. The Trappe forcefield was employed for ethane ${ }^{12}$ and ethene ${ }^{13}$. All van der Waals interactions were truncated and shifted to 
zero at the cutoff distance of $14 \AA$. Atomic charges of MOF-801 were adopted those from UiO-66 in the previous work ${ }^{14}$ while atomic charge of hydrogen on organic linkers were adjusted to keep the MOF neutral. For each GCMC simulation, a total of 200000 MC cycles were performed with random translation, rotation, and insertion/deletion moves. Periodic boundary conditions were applied in all directions. At $308 \mathrm{~K}$, GCMC was performed with $1 \mathrm{kPa}$ for both ethane and ethene. In addition, to compare the diffusion coefficient without effect of difference in density, configuration containing 15 ethane (or ethane) molecules in the supercell was prepared using Monte Carlo simulations.

Then, diffusion coefficient was estimated by performing molecular dynamics runs (MD) using the LAMMPS (Large-scale Atomic/Molecular Massively Parallel Simulator) ${ }^{15}$ with a canonical ensemble (NVT) at a fixed temperature of $400 \mathrm{~K}$. During MD, MOF-801 framework was described by MM3 force field ${ }^{16}$ with the parameters adopted from UiO-66 developed in a previous work ${ }^{6}$. The atoms types or forcefield parameters used in our MD simulations is shown in Figure S18 or summarized in Table S5-11, respectively. The MM3 forcefield was also employed for ethane and ethane. In MD simulations, the van der Waals and Coulombic interactions were subject to a $14 \AA$ cutoff. The simulations cells were firstly relaxed with NVT ensemble during 1 ns at 400 $\mathrm{K}$ followed by $10 \mathrm{~ns}$ at $400 \mathrm{~K}$ until the 3 -dimensional mean-squared displacements $(M S D=$ $\left.\left\langle(r(t))^{2}\right\rangle\right)$ of gas molecules were sufficiently converged. For each case, the final trajectories within 5 ns were used for estimating diffusion coefficients $(D)$ by fitting MD results to the Einstein relation of $\left\langle(r(t))^{2}\right\rangle=6 D t$, where $t$ is MD simulation time. 


\section{Gas permeability measurements}

The single gas permeation was performed at $35^{\circ} \mathrm{C}$ with a home-built variable-pressure constantvolume setup (Figure S21). Membranes were activated by heating at $100{ }^{\circ} \mathrm{C}$ under high vacuum overnight before testing. Then the pre-activated membrane was placed on the central hole of a custom-made brass disk sealed by heat-resist epoxy resin and then housed in a membrane cell. The upstream pressure can be read by a high-accuracy gauge. Downstream was kept under vacuum until measurement. In a typical permeation measurement procedure, the entire permeation system was degassed under high vacuum for at least 3 hours. Then the leak rate of downstream was determined by measuring the pressure for 10 minutes while keep the pumping off. The leak test was performed for at least 2 times. Permeation was measured for 3 minutes at each pressure point. The average results can be obtained by measuring three films at one pressure point. The permeability can be calculated by the equation (2).

$$
\mathrm{P}=\frac{\mathrm{lV} \text { cell }}{\mathrm{A} \Delta_{\mathrm{p}} \mathrm{RT}}\left[(\mathrm{dp} / \mathrm{dt})_{\mathrm{SS}}-(\mathrm{dp} / \mathrm{dt})_{\text {leak }}\right]
$$

Where $\mathrm{P}$ is the permeability (1 Barrer $\left.=10^{-10} \mathrm{cc}(\mathrm{STP}) \mathrm{cm} \mathrm{cm}^{-2} \mathrm{~s}^{-1} \mathrm{cmHg}^{-1}\right), \mathrm{l}$ is the thickness of the film, $\mathrm{A}$ is the effective area of the membrane, $\mathrm{V}_{\text {cell }}$ is the downstream volume, $\mathrm{T}$ is the operating temperature in kelvin, $(\mathrm{dp} / \mathrm{dt})_{\mathrm{ss}}$ is the steady-state permeation rate, and $(\mathrm{dp} / \mathrm{dt})_{\text {leak }}$ is the leak rate. $\Delta \mathrm{p}$ is the pressure difference between upstream and downstream. $\mathrm{R}$ is the gas constant.

The ideal selectivity of pure gas A and B can be calculated by using the equation (3): 


$$
\alpha=\frac{P_{A}}{P_{B}}
$$

where $\mathrm{P}_{\mathrm{A}}$ and $\mathrm{P}_{\mathrm{B}}$ is the permeability of pure gas $\mathrm{A}$ and $\mathrm{B}$, respectively.

\section{Permeability, Solubility and Diffusivity ${ }^{17}$}

To further elucidate the mechanism of increased selectivity and permeability, permeability is expressed as the product of the average effective diffusion coefficient(D) and sorption coefficient (S) of the gas within the membrane:

$$
P=D \cdot S
$$

The sorption coefficient represents the thermodynamic contribution to transport, and it can be calculated by the equation (5):

$$
S=\frac{c}{f}
$$

where $c$ and $f$ are the concentration of a gas adsorbed in the sample and the corresponding upstream fugacity driving force of the gas, respectively. The adsorbed gas concentration in membranes was described by the dual-mode sorption model which is fitted to the measured sorption isotherms (Figure S20b) as below:

$$
c=c_{D}+c_{H}=k_{D} \cdot f+\frac{C_{H} \cdot b \cdot f}{1+b \cdot f}
$$

Where $c_{D}$ is the Henry's law or dissolved mode penetrant concentration, $c_{H}$ is the penetrant concentration in the Langmuir mode or holefilling sorption mode, $k_{D}$ is the Henry's law sorption 
coefficient, $C_{H}$ is the Langmuir capacity constant, and $\mathrm{b}$ is the Langmuir affinity constant. Based on the gas solubility (S) and permeability (P), the diffusion coefficient (D) can be calculated by by the equation (4).

\section{Maxwell model}

The gas transport in mixed-matrix materials were describe by Maxwell model. Further, the permeability in dispersed molecular sieve particles can be calculated. Maxwell model is given by: ${ }^{18}$

$$
P_{\text {Maxwell }}=P_{\mathrm{p}} \frac{P_{\mathrm{s}}+2 P_{\mathrm{p}}-2 \phi_{\mathrm{s}}\left(P_{\mathrm{p}}-P_{\mathrm{s}}\right)}{P_{\mathrm{s}}+2 P_{\mathrm{p}}+\phi_{\mathrm{s}}\left(P_{\mathrm{p}}-P_{\mathrm{s}}\right)}
$$

In this equation, $P_{\text {Maxwell, }} P_{\mathrm{p}}$ and $P_{S}$ represent the permeability of the MMMs, the polymer matrix and the dispersed molecular sieve particles. $\phi_{\mathrm{s}}$ the volume fraction of the molecular sieve.

\section{Scherrer equation ${ }^{19}$}

The average crystallite size of Ni-MOF-74 was estimated by Scherrer equation:

$$
D=\frac{K \lambda}{\beta \cos \theta}
$$

In this equation, $D$ is the average thickness in vertical direction of the crystal face (average crystallite size), $K$ is Scherrer constant. (if $\beta$ is the full width at half maximum intensity of the peak, $K=0.89$. if $\beta$ is integral height to width of the diffraction peak, $K=0.89$ ), $\lambda$ is the wavelength of X-ray, $\beta$ is the half high width of the diffraction peak of the sample, $\theta$ is diffraction angle(deg). 


\section{Section S4. Supplemental Figures and Tables}
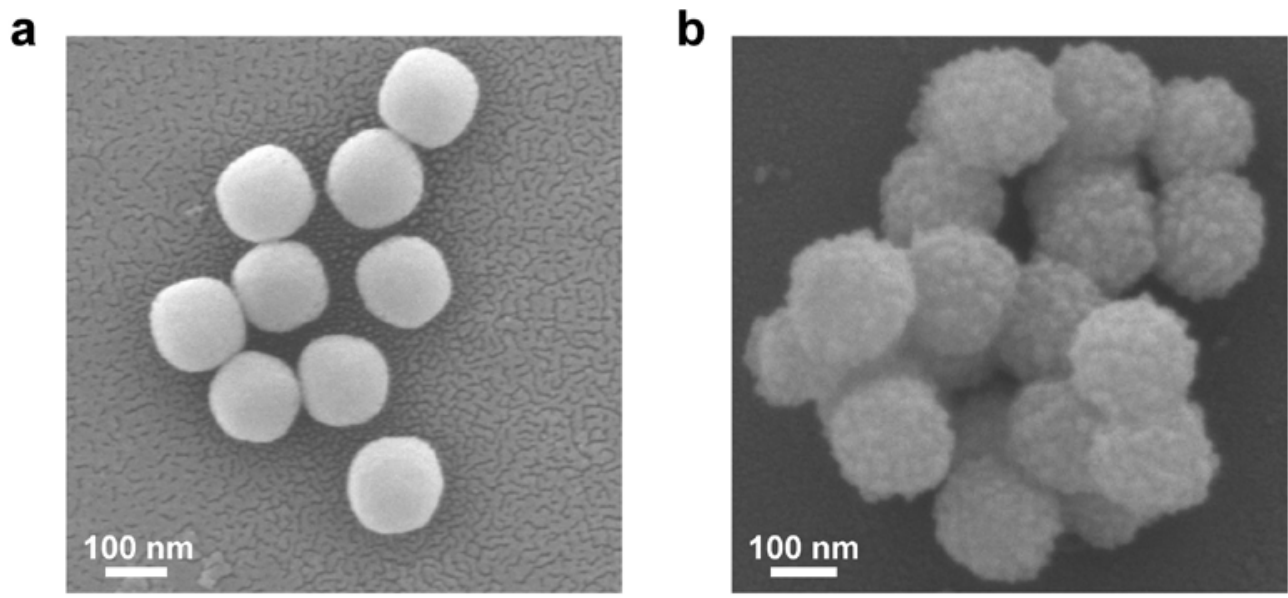

Figure S1. The SEM images of MOF-801 (a) and MOF-801@Ni-MOF-74 (b). 

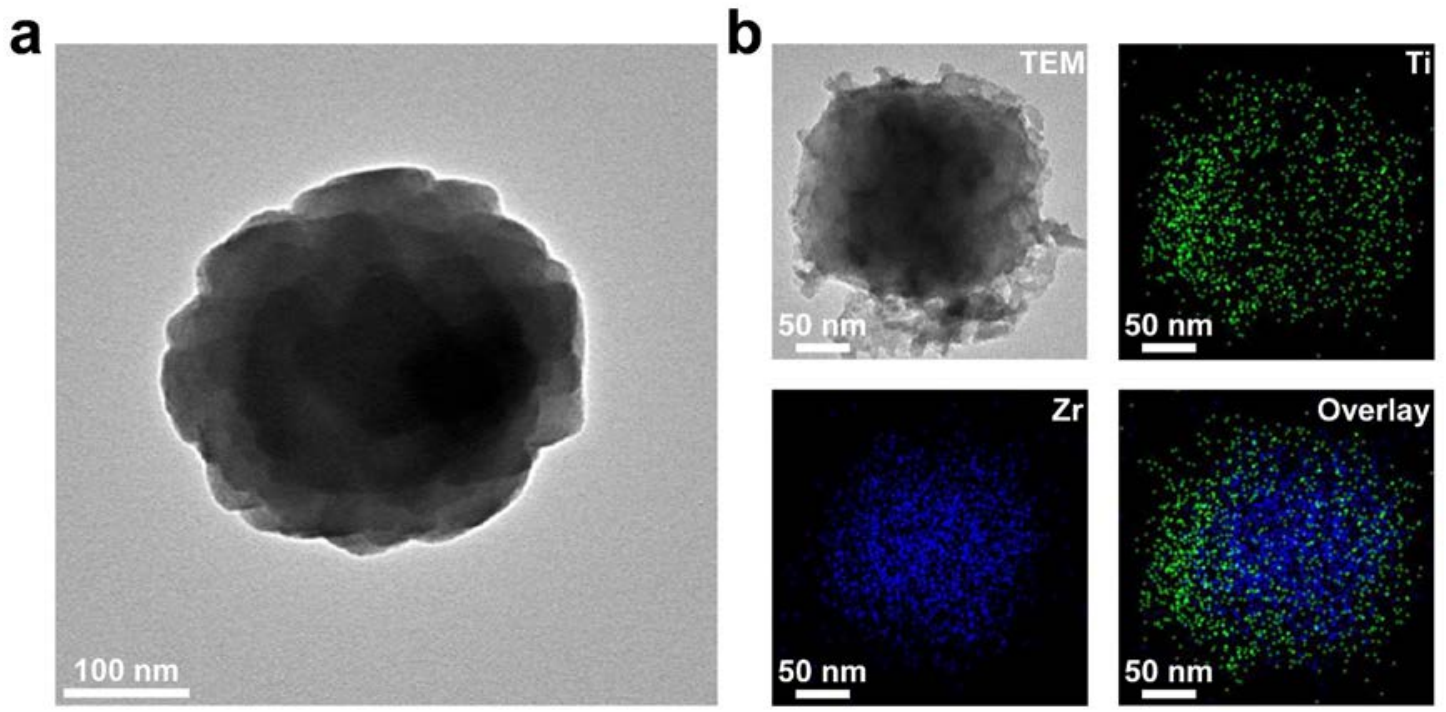

C

d
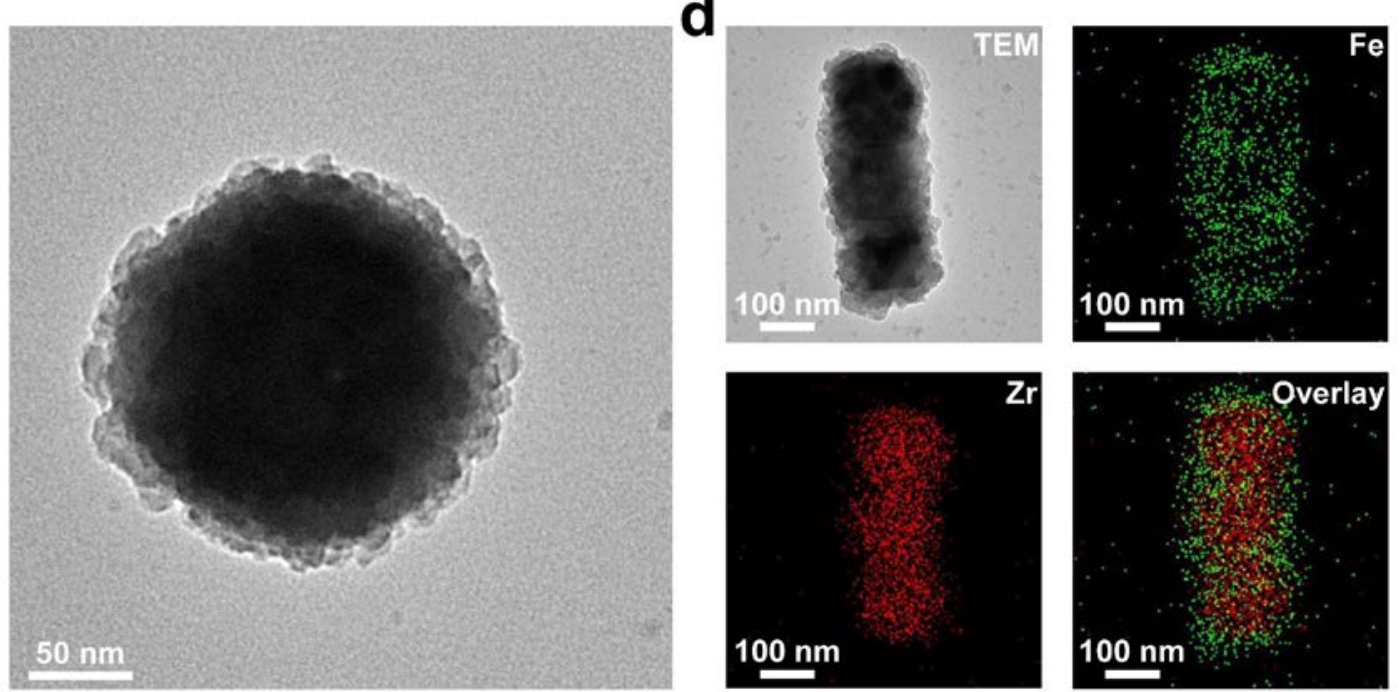

Figure S2. (a) TEM images of UiO-66@MOF-801. (b) TEM images and EDS elemental mapping images of UiO-66@MIL-125(Ti). (c) TEM images of MOF-801@UiO-66. (d) TEM images and EDS elemental mapping images of UiO-66@MIL-100(Fe). 

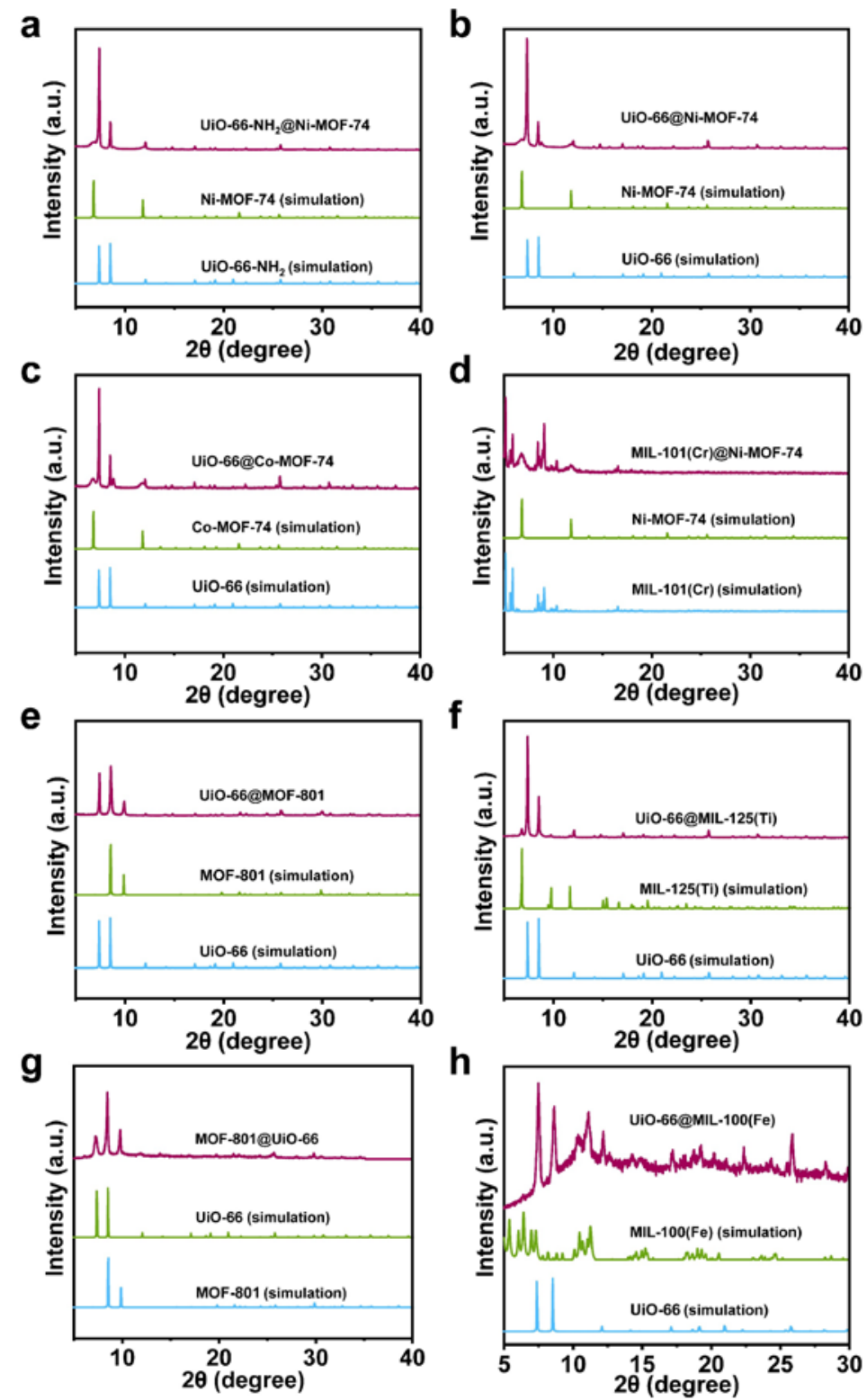

Figure S3. Powder X-ray diffraction patterns of UiO-66-NH2@Ni-MOF-74 (a), UiO-66@Ni-

MOF-74 (b), UiO-66@Co-MOF-74 (c), MIL-101(Cr)@Ni-MOF-74 (d), UiO-66@MOF-801 (e), UiO-66@MIL-125(Ti) (f), MOF-801@UiO-66 (g) and UiO-66@MIL-100(Fe) (h). 


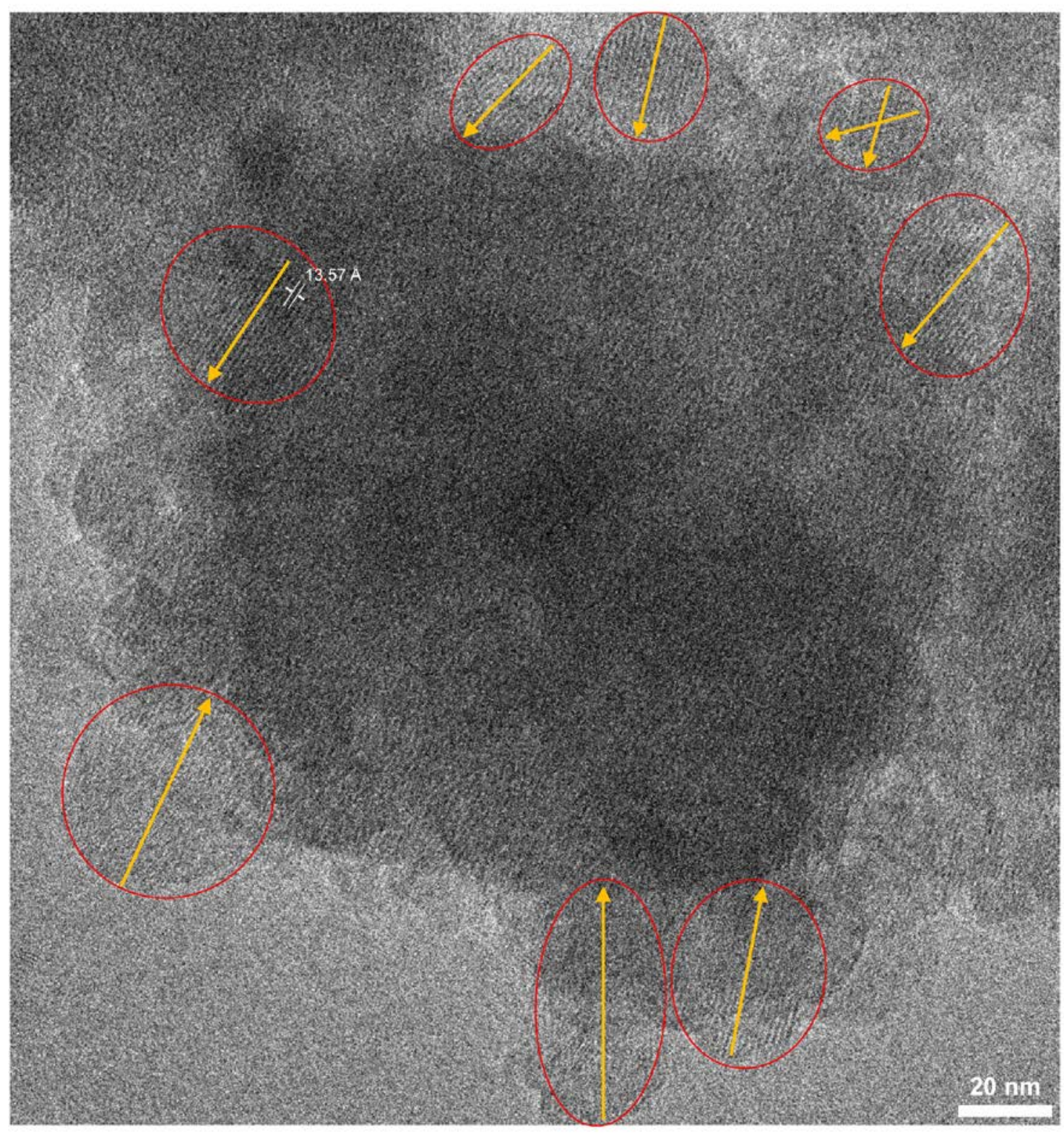

Figure S4. HRTEM image of 801@74. The red circles indicate the outline of single Ni-MOF-74 crystal, the yellow arrows indicate the direction of Ni-MOF-74 1D pore alignment. 

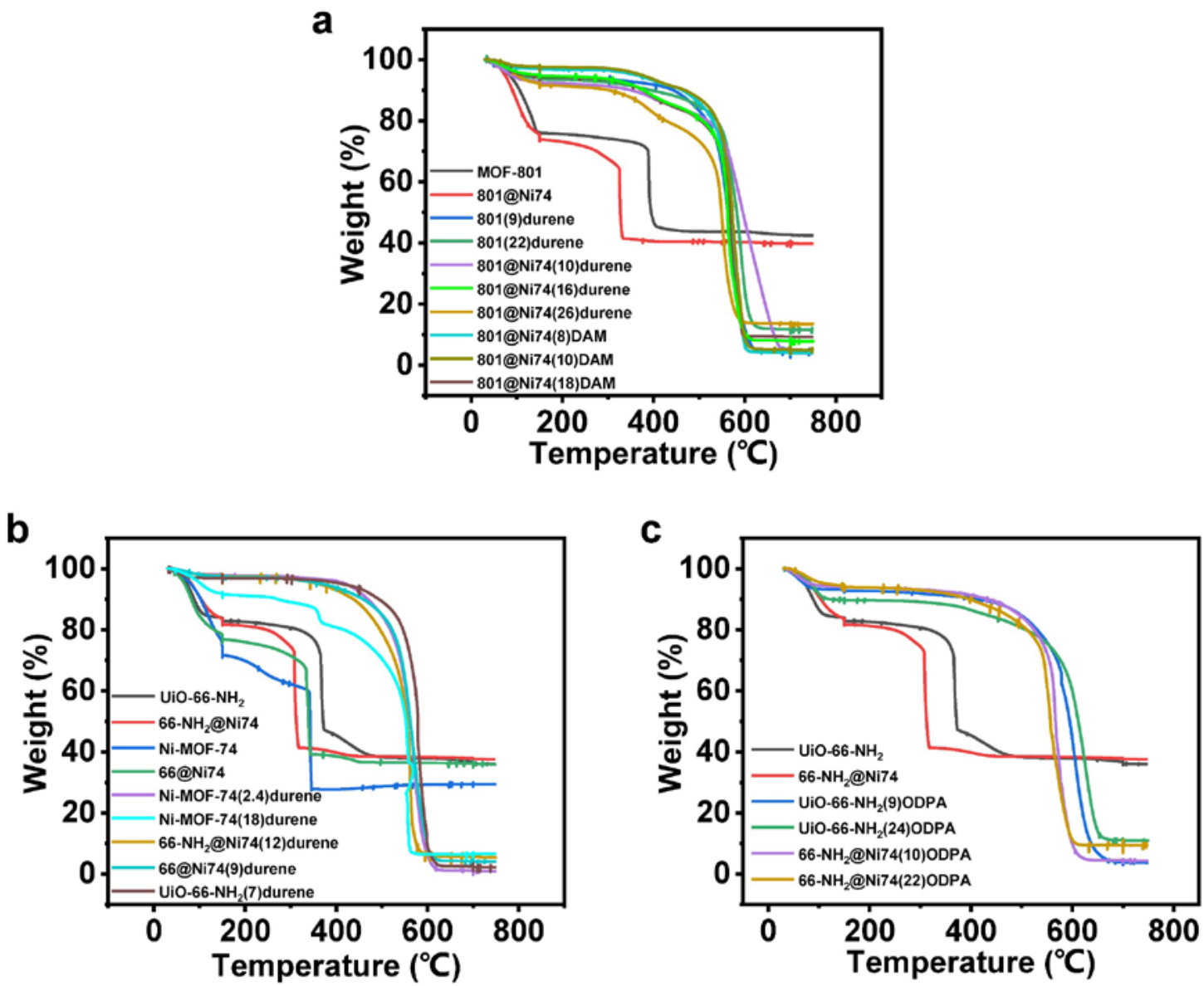

Figure S5. TGA of neat MOF-801, 801@Ni74, UiO-66-NH2, 66-NH2@Ni74, 66@Ni74, NiMOF-74 and MMMs. The MOF loading values were summarized in Table S1. 
Table S1. The calculated MOF loading of hybrid membranes from TGA.

\begin{tabular}{|c|c|c|c|}
\hline MMMs & $\begin{array}{c}\text { MOF } \\
\text { loading (\%) }\end{array}$ & MMMs & $\begin{array}{c}\text { MOF } \\
\text { loading (\%) }\end{array}$ \\
\hline 801(9)durene & 8.7 & Ni-MOF-74(18)durene & 17.5 \\
\hline 801(22)durene & 22.1 & 801@Ni74(8)DAM & 7.7 \\
\hline 801@Ni74(10)durene & 10.0 & 801@Ni74(10)DAM & 9.8 \\
\hline 801@Ni74(16)durene & 16.1 & 801@Ni74(18)DAM & 18.1 \\
\hline 801@Ni74(26)durene & 26.4 & $\mathrm{UiO}-66-\mathrm{NH}_{2}(9) \mathrm{ODPA}$ & 9.2 \\
\hline UiO-66- $\mathrm{NH}_{2}$ (7)durene & 6.9 & UiO-66- $\mathrm{NH}_{2}(24) \mathrm{ODPA}$ & 24.2 \\
\hline 66-NH2@Ni74(12)durene & 12.3 & 66-NH2@Ni74(10)ODPA & 10.1 \\
\hline 66@Ni74(9)durene & 9.1 & 66-NH2@Ni74(22)ODPA & 21.7 \\
\hline Ni-MOF-74(2.4)durene & 2.4 & & \\
\hline
\end{tabular}



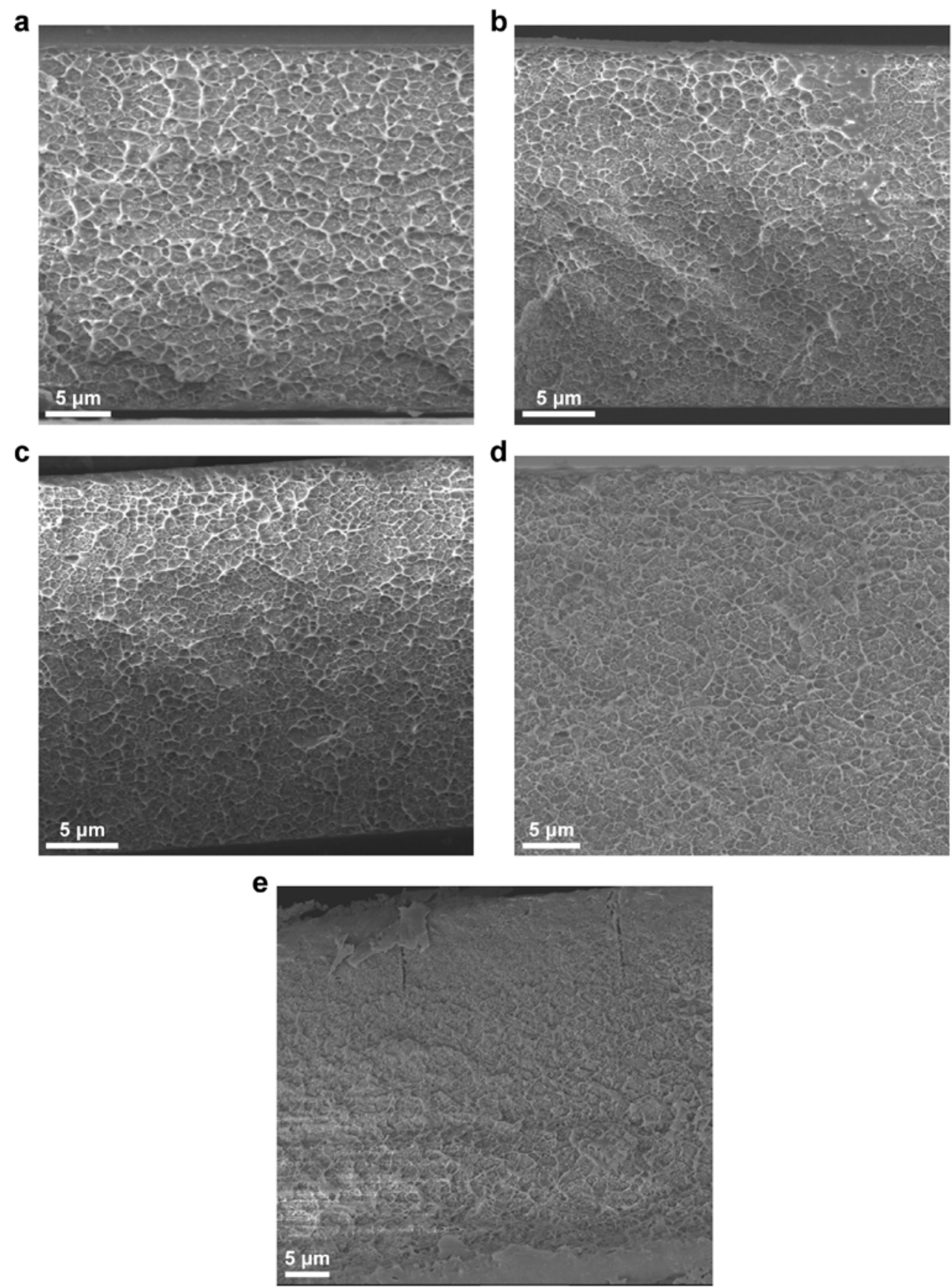

Figure S6. Cross-sectional SEM images of 801(9)durene (a), 801(22)durene (b), 801@Ni74(10)durene (c), 801@Ni74(16)durene (d) and 801@Ni74(26)durene (e). Samples for SEM measurement fractured in the liquid nitrogen. 
a

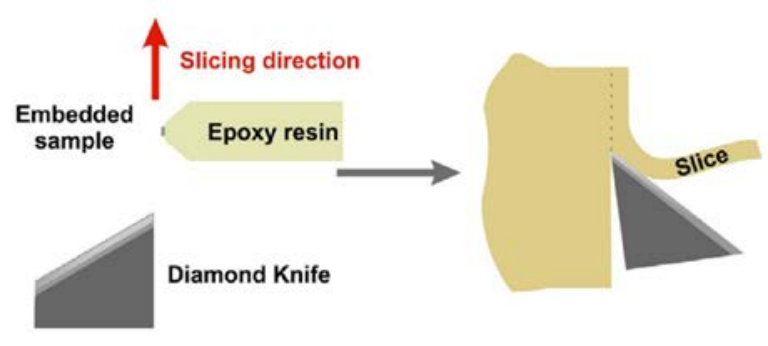

b

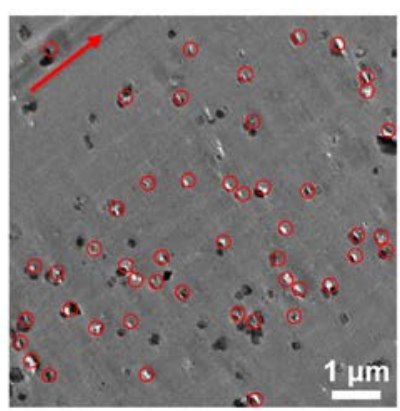

Figure S7. (a) Scheme of cutting ultrathin slices by using ultramicrotome. (b) TEM image of ultrathin slices of UiO-66- $\mathrm{NH}_{2}(7)$ durene. The red arrows indicate the cutting direction, and the red circles highlight the teared interface. 

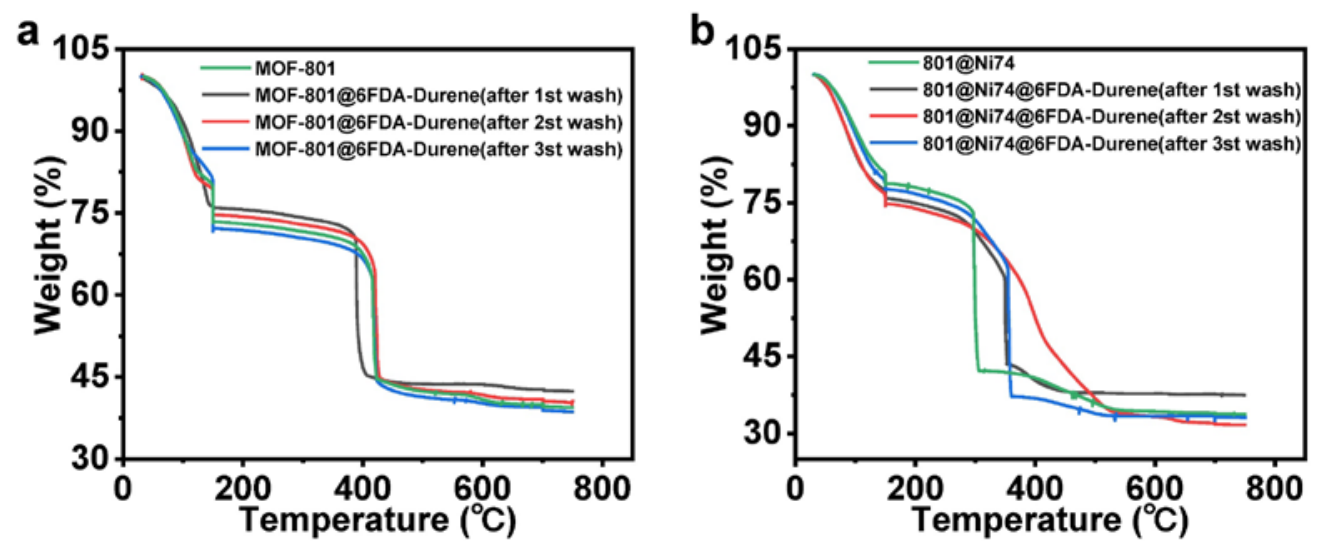

Figure S8. (a) TGA of neat MOF-801 and MOF-801@6FAD-durene after being washed 1/2/3 times with chloroform. (b) TGA of neat 801@Ni74 and 801@Ni74@6FAD-durene after being washed 1/2/3 times with chloroform. 


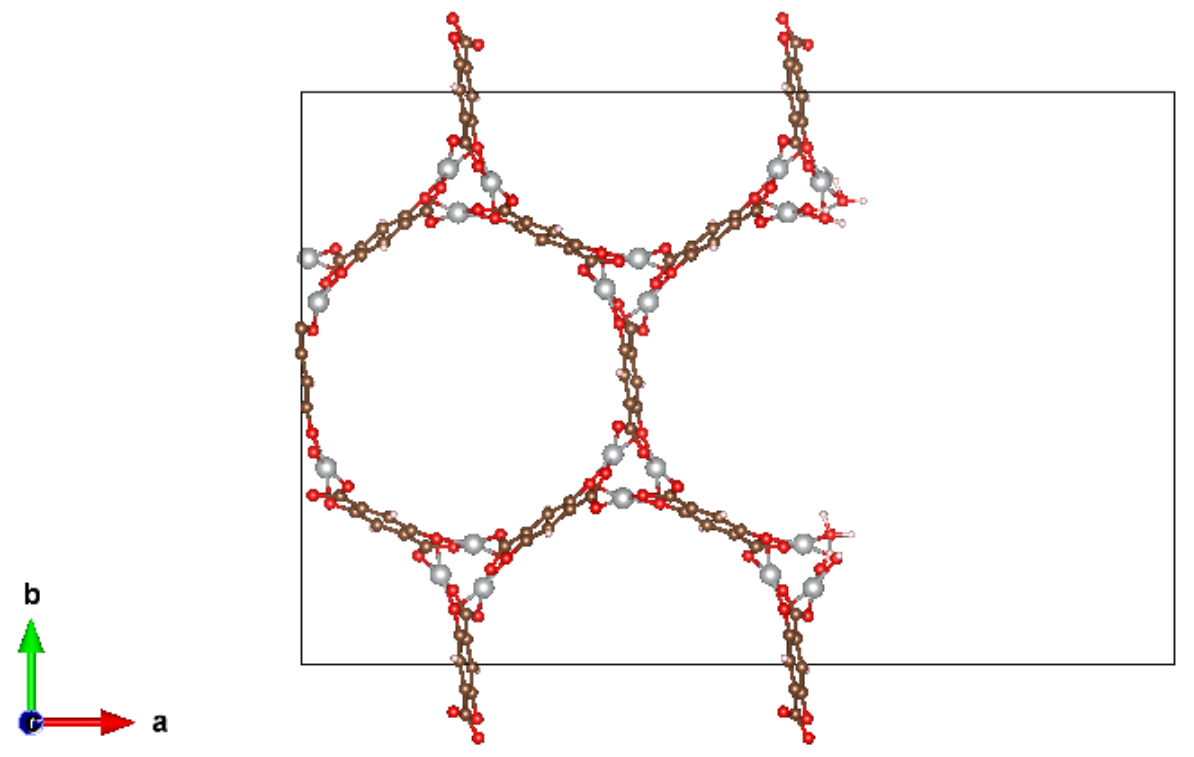

Figure S9. Unit surface cell of Ni-MOF-74. 


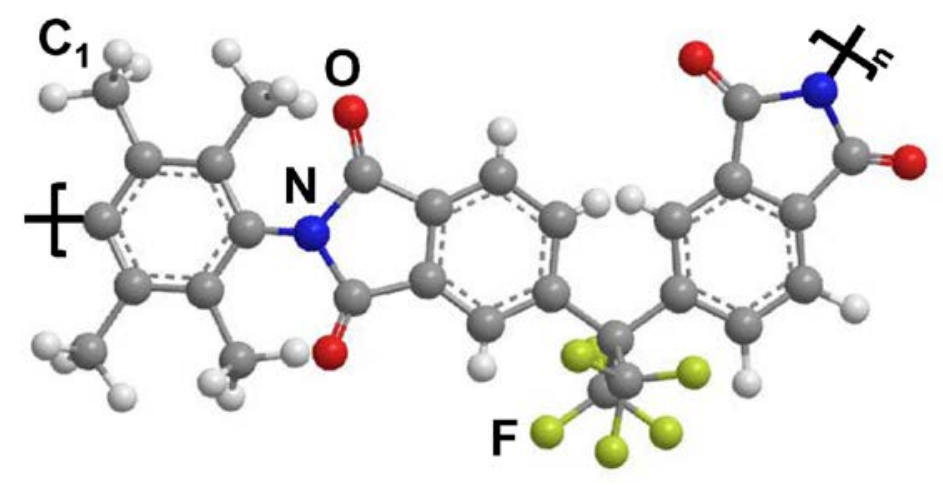

Figure S10. Unit of 6FDA-durene 


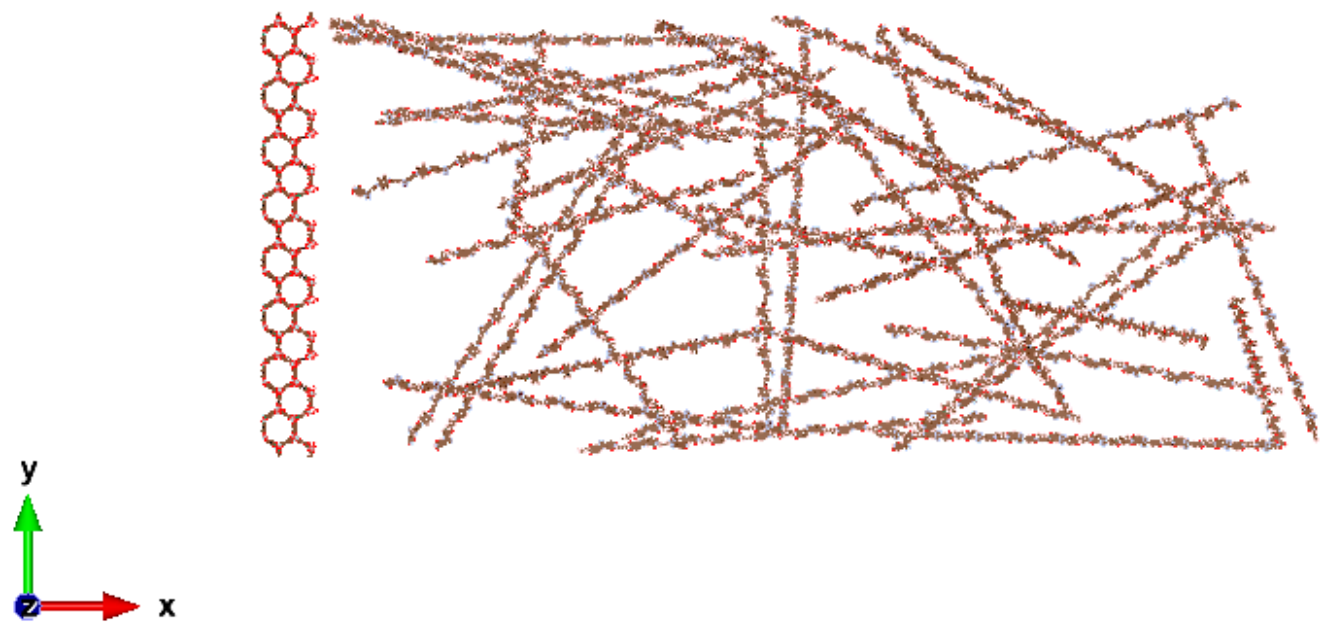

Figure S11. Initial system box. 

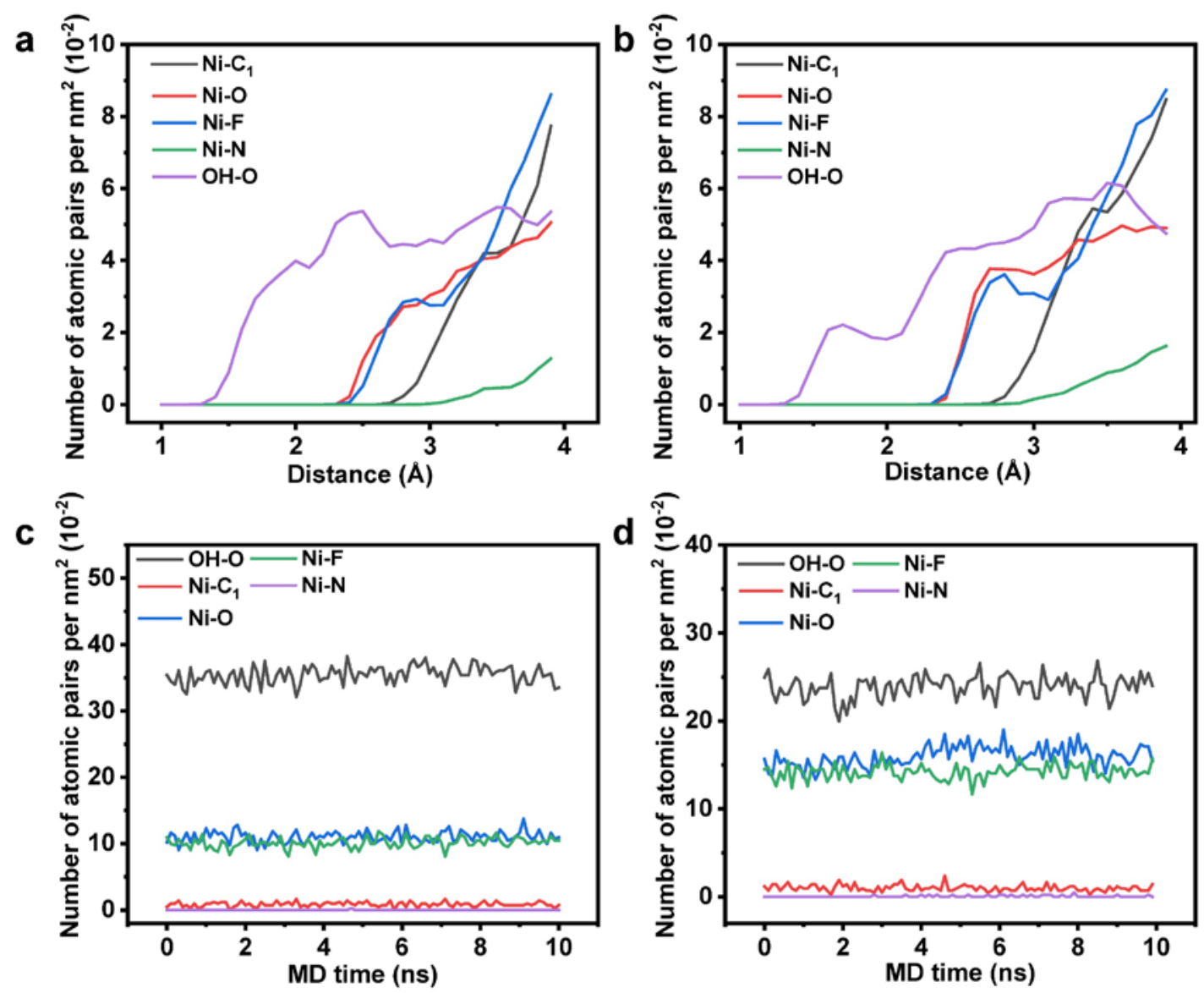

Figure S12. Number of atomic pairs between Ni/OH on Ni-MOF-74 and various atoms on 6FDA-durene per nm² Ni-MOF-74 (100) facet surface at equilibrium state for (a) partially activated and (b) fully activated Ni-MOF-74. The y axis number represents the total number of atomic pairs within 0.1 Å of each interval. Numbers of pairs as time goes for (c) partially activated and (d) fully activated Ni-MOF-74 within 3 or 2.5 angstrom among Ni-MOF-74 and polymers. 


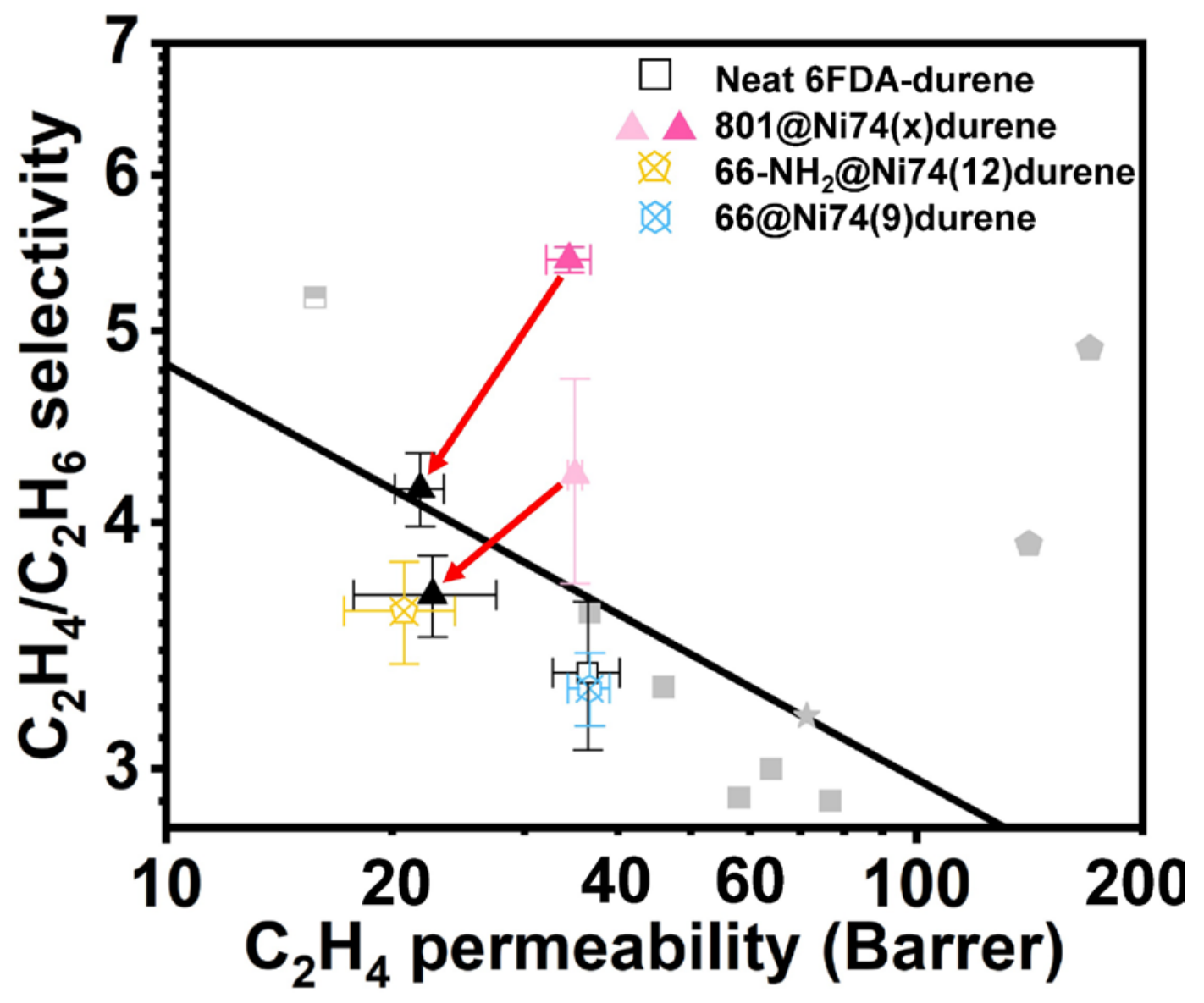

Figure S13. $\mathrm{C}_{2} \mathrm{H}_{4} / \mathrm{C}_{2} \mathrm{H}_{6}$ transport properties of the neat 6FDA-DAM, 66- $\mathrm{NH}_{2} @ \mathrm{Ni} 74(12) d u r e n e$, $66 @ N i 74(9) d u r e n e$ and 801@Ni74(x)durene ( $\mathrm{x}=10$ and 16) under 2 bar at $35{ }^{\circ} \mathrm{C}$. The sample labeled "blocked metal sites" was exposed to water vapor for extended period of time and then evacuated in the permeation cell at $80^{\circ} \mathrm{C}$ for 1 day before running permeation experiments (black triangle). 
Table S2. Single gas permeation properties of neat polymer and MMMs.

\begin{tabular}{|c|c|c|c|c|c|c|}
\hline \multirow{2}{*}{ Membranes } & \multicolumn{4}{|c|}{ Permeability (Barrer) } & \multicolumn{2}{|c|}{ Ideal selectivity } \\
\hline & $\mathrm{CH}_{4}$ & $\mathrm{CO}_{2}$ & $\mathrm{C}_{2} \mathrm{H}_{6}$ & $\mathrm{C}_{2} \mathrm{H}_{4}$ & $\mathrm{CO}_{2} / \mathrm{CH}_{4}$ & $\mathrm{C}_{2} \mathrm{H}_{4} / \mathrm{C}_{2} \mathrm{H}_{6}$ \\
\hline 6FDA-durene & - & - & $10.95 \pm 1.9$ & $36.44 \pm 3.71$ & - & $3.36 \pm 0.29$ \\
\hline 801(9)durene & - & - & $11.82 \pm 2.57$ & $40.53 \pm 4.53$ & - & $3.47 \pm 0.34$ \\
\hline 801(22)durene & - & - & $12.81 \pm 2.34$ & $48.05 \pm 7.32$ & - & $3.77 \pm 0.13$ \\
\hline 801@Ni74(10)durene & - & - & $8.37 \pm 1.13$ & $35.03 \pm 0.76$ & - & $4.23 \pm 0.50$ \\
\hline 801@Ni74(10)durene $\left(\mathrm{H}_{2} \mathrm{O}\right)$ & & & $6.17 \pm 1.40$ & $22.62 \pm 4.87$ & & $3.67 \pm 0.17$ \\
\hline 801@Ni74(16)durene & & & $6.33 \pm 0.50$ & $34.40 \pm 2.36$ & & $5.44 \pm 0.08$ \\
\hline 801@Ni74(16)durene $\left(\mathrm{H}_{2} \mathrm{O}\right)$ & & & $21.78 \pm 1.64$ & $5.24 \pm 0.40$ & & $4.16 \pm 0.18$ \\
\hline 801@Ni74(26)durene & - & - & $4.48 \pm 0.98$ & $26.15 \pm 3.17$ & - & $5.91 \pm 0.56$ \\
\hline 66-NH2@Ni74(12)durene & - & - & $11.14 \pm 1.15$ & $36.62 \pm 2.34$ & - & $3.30 \pm 0.14$ \\
\hline Ni-MOF-74(2.4) durene & - & - & $9.84 \pm 0.91$ & $30.21 \pm 2.96$ & - & $3.07 \pm 0.02$ \\
\hline Ni-MOF-74(18) durene & & & $12.67 \pm 1.70$ & $40.05 \pm 3.74$ & & $3.17 \pm 0.18$ \\
\hline 66@Ni74(9)durene & - & - & $5.80 \pm 1.35$ & $20.73 \pm 3.48$ & - & $3.61 \pm 0.21$ \\
\hline 6FDA-DAM & - & - & $5.84 \pm 0.43$ & $19.75 \pm 1.07$ & - & $3.39 \pm 0.13$ \\
\hline 801@Ni74(8)DAM & - & - & $5.58 \pm 0.49$ & $25.03 \pm 1.53$ & - & $4.49 \pm 0.15$ \\
\hline 801@Ni74(10)DAM & & & $6.76 \pm 0.53$ & $31.16 \pm 3.02$ & & $4.60 \pm 0.14$ \\
\hline 801@Ni74(18)DAM & - & - & $6.23 \pm 0.75$ & $33.16 \pm 2.38$ & - & $5.34 \pm 0.26$ \\
\hline ODPA-DAM & $2.18 \pm 0.29$ & $60.91 \pm 4.84$ & - & - & $28.24 \pm 3.47$ & - \\
\hline UiO-66-NH ${ }_{2}(9) O D P A$ & $5.24 \pm 0.32$ & $127.72 \pm 10.66$ & - & - & $24.39 \pm 1.66$ & - \\
\hline $\mathrm{UiO}-66-\mathrm{NH}_{2}(24) \mathrm{ODPA}$ & $6.15 \pm 0.43$ & $148.38 \pm 4.32$ & - & - & $24.20 \pm 1.07$ & - \\
\hline 66-NH2@Ni74(10)ODPA & $2.39 \pm 0.67$ & $75.00 \pm 14.26$ & - & - & $32.02 \pm 3.48$ & - \\
\hline 66-NH2@Ni74(22)ODPA & $2.04 \pm 0.17$ & $89.58 \pm 4.06$ & - & - & $44.13 \pm 2.70$ & - \\
\hline
\end{tabular}




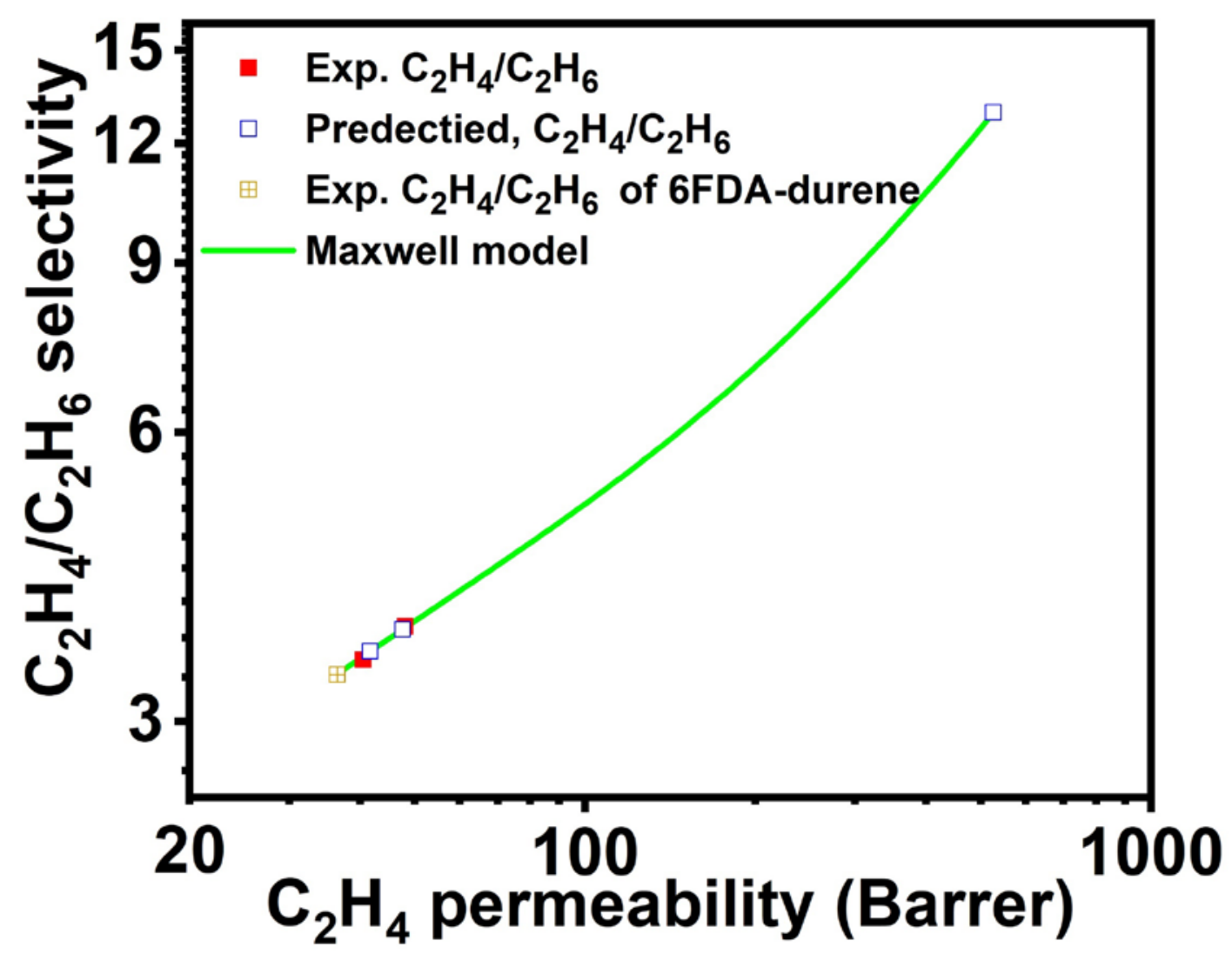

Figure S14. Fitting results of experimental $\mathrm{C}_{2} \mathrm{H}_{4} / \mathrm{C}_{2} \mathrm{H}_{6}$ selectivity of neat PI and low filler loading points 801(9)durene and 801(22)durene by using Maxwell model. All the permeation data were obtained under 2 bar at $35^{\circ} \mathrm{C}$. 
Table S3. Values of gas solubility, diffusivity, sorption selectivity and diffusion selectivity of neat 6FDA-durene, 801(22)durene and 801@Ni74(16)durene at 2 bar and $35{ }^{\circ} \mathrm{C}$.

\begin{tabular}{c|c|c|c|c|c|c}
\hline & \multicolumn{2}{|c|}{$\mathrm{C}_{2} \mathrm{H}_{6}$} & \multicolumn{2}{c|}{$\mathrm{C}_{2} \mathrm{H}_{4}$} & \multicolumn{2}{c}{$\mathrm{C}_{2} \mathrm{H}_{4} / \mathrm{C}_{2} \mathrm{H}_{6}$ selectivity } \\
\cline { 2 - 7 } & $\begin{array}{c}\text { Solubility }\left(10^{-2}\right. \\
\mathrm{cm}^{3}(\mathrm{STP}) /\left(\mathrm{cm}^{3} \cdot \mathrm{cmHg}\right)\end{array}$ & $\begin{array}{c}\text { Diffusivity } \\
\left(10^{-10} \mathrm{~cm}^{2} / \mathrm{s}\right)\end{array}$ & $\begin{array}{c}\text { Solubility }\left(10^{-2}\right. \\
\left.\mathrm{cm}^{3}(\mathrm{STP}) /\left(\mathrm{cm}^{3} \cdot \mathrm{cmHg}\right)\right)\end{array}$ & $\begin{array}{c}\text { Diffusivity }\left(10^{-}\right. \\
\left.{ }^{10} \mathrm{~cm}^{2} / \mathrm{s}\right)\end{array}$ & Sorption & Diffusion \\
\hline Neat 6FDA-Durene & 19.15 & $57.17 \pm 9.92$ & 20.84 & $174.85 \pm 17.80$ & 1.09 & $3.09 \pm 0.27$ \\
801(22)durene & 25.53 & $50.16 \pm 9.18$ & 26.63 & $180.41 \pm 27.48$ & 1.04 & $3.61 \pm 0.13$ \\
801@Ni74(16)durene & 24.92 & $25.40 \pm 3.00$ & 25.57 & $134.53 \pm 9.24$ & 1.03 & $5.30 \pm 0.08$ \\
\hline
\end{tabular}




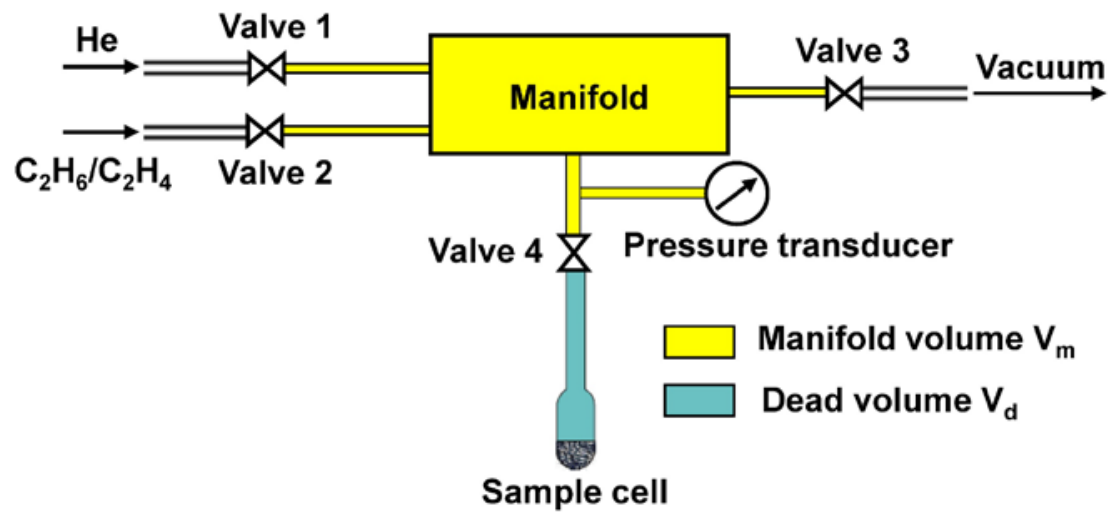

Figure S15. Schematic illustration of pressure decay method. 

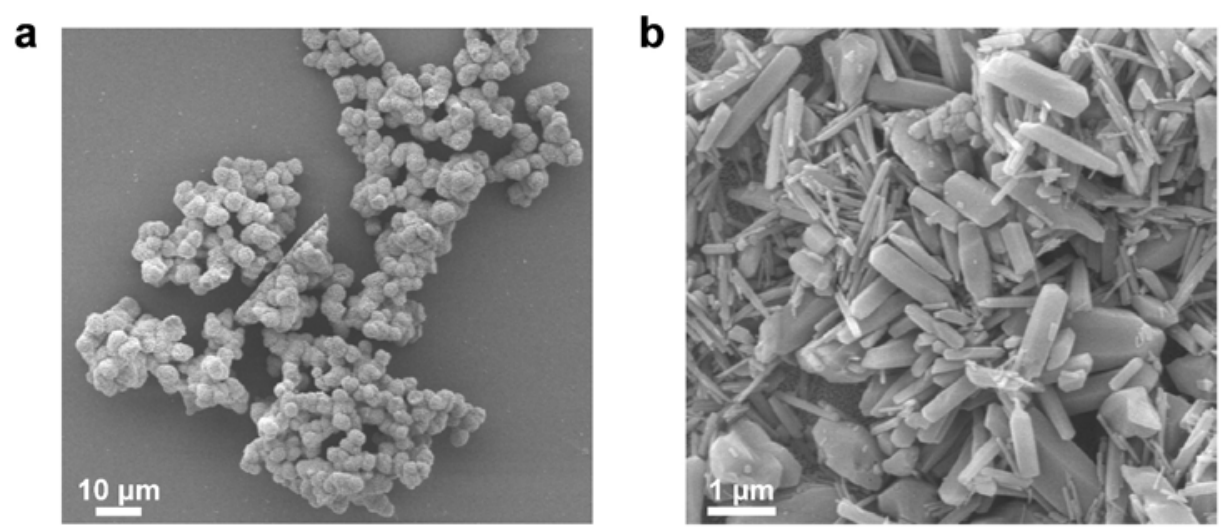

Figure S16. The SEM images of large size MOF-801(a) and Ni-MOF-74 (b). 

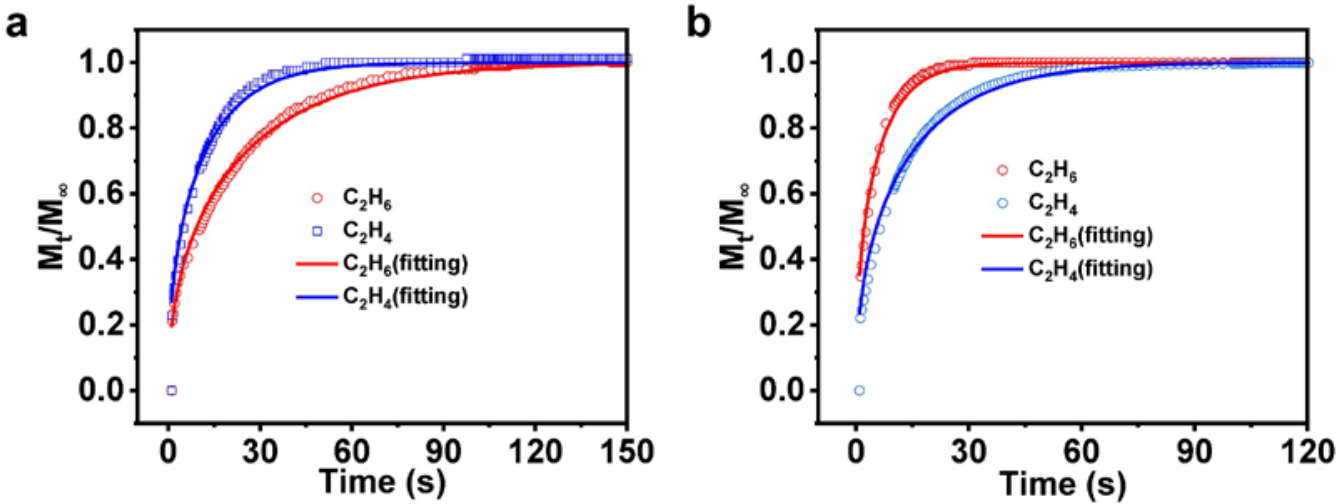

Figure S17. Kinetic curves of $\mathrm{C}_{2} \mathrm{H}_{6}$ and $\mathrm{C}_{2} \mathrm{H}_{4}$ uptake for MOF-801(a) and Ni-MOF-74(b) at 308 $\mathrm{k}\left(\mathrm{P} / \mathrm{P}_{0}=0.003\right)$. The solid line shows the fitting curves using the Fickian diffusion model. 
Table S4. Values of the Fickian diffusion model parameters for $\mathrm{C}_{2} \mathrm{H}_{6}$ and $\mathrm{C}_{2} \mathrm{H}_{4}$ uptake for MOF801and Ni-MOF-74.

\begin{tabular}{c|c|c|c|c|c}
\hline \multirow{2}{*}{$\begin{array}{c}\text { Initial } \\
\text { pressure }\end{array}$} & Sample & \multicolumn{2}{|c|}{$\mathrm{D}_{\mathrm{s}} / r^{2}\left(\mathrm{~s}^{-1}\right)$} & \multicolumn{2}{c}{$\begin{array}{c}\mathrm{R}^{2} \text { (regression } \\
\text { coefficient) }\end{array}$} \\
\cline { 3 - 6 } & & $\mathrm{C}_{2} \mathrm{H}_{6}$ & $\mathrm{C}_{2} \mathrm{H}_{4}$ & $\mathrm{C}_{2} \mathrm{H}_{6}$ & $\mathrm{C}_{2} \mathrm{H}_{4}$ \\
\hline \multirow{2}{*}{$0.003 \mathrm{P}_{0}$} & MOF-801 & $3.27 \times 10^{-3}$ & $6.84 \times 10^{-3}$ & 0.9823 & 0.9534 \\
& Ni-MOF-74 & $1.36 \times 10^{-2}$ & $5.55 \times 10^{-3}$ & 0.9035 & 0.9740 \\
\hline
\end{tabular}




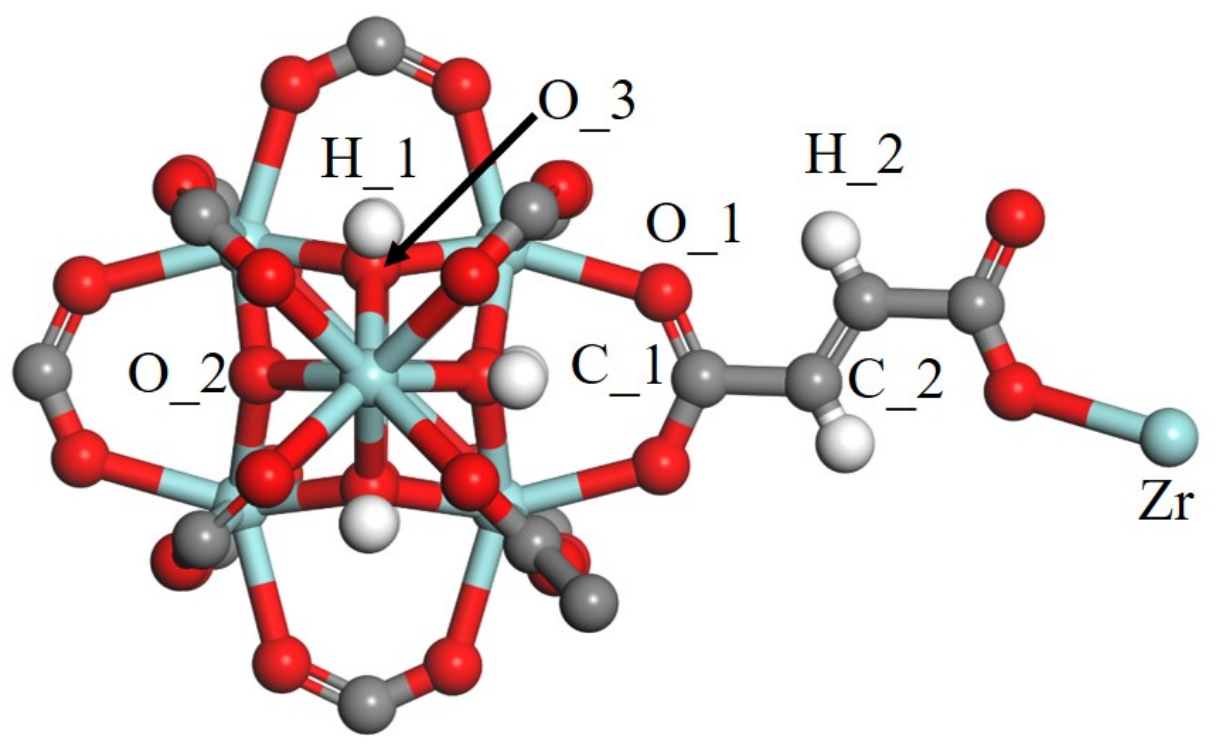

Figure S18. Atoms types of MOF-801. Light cyan, dark gray, red, or white ball represents zirconium, carbon, oxygen, or hydrogen atom, respectively. 
Table S5. Mass, atomic charge and van der Waals (vdW) potential energy $\left(E_{v d w}\right)$ parameters of atoms in MOF-801. $E_{v d w}=\varepsilon\left(184000 e^{-12\left(\frac{r_{0}}{r}\right)-2.25\left(\frac{r_{0}}{r}\right)^{6}}\right)$

\begin{tabular}{c|cccc}
\hline Atom type & mass(g/mol) & charge(C/mol) & $\boldsymbol{r}_{\mathbf{0}}(\AA)$ & $\boldsymbol{\varepsilon}(\mathbf{k c a l} / \mathbf{m o l})$ \\
\hline Zr & 91.224 & 2.601 & 3.520 & 0.367 \\
C_1 & 12.000 & 1.576 & 1.940 & 0.056 \\
C_2 & 12.000 & -0.058 & 1.960 & 0.056 \\
O_1 & 15.995 & -1.181 & 1.820 & 0.059 \\
O_2 & 15.995 & -1.189 & 1.820 & 0.059 \\
O_3 & 15.955 & -1.242 & 1.820 & 0.059 \\
H_1 & 1.008 & 0.622 & 1.600 & 0.020 \\
H_2 & 1.008 & 0.099 & 1.620 & 0.020 \\
\hline
\end{tabular}


Table S6. Mass, atomic charge and van der Waals (vdW) potential energy $\left(E_{v d w}\right)$ parameters of atoms in ethane and ethene. $E_{v d w}=\varepsilon\left(184000 e^{-12\left(\frac{r_{0}}{r}\right)-2.25\left(\frac{r_{0}}{r}\right)^{6}}\right)$

\begin{tabular}{c|ccccc}
\hline Molecule & Atom Types & mass(g/mol) & charge(C/mol) & $\boldsymbol{r}_{\mathbf{0}}(\boldsymbol{\AA})$ & $\boldsymbol{\varepsilon}(\mathbf{k c a l} / \mathbf{m o l})$ \\
\hline $\mathrm{C}_{2} \mathrm{H}_{6}$ & C2H6_C & 12.000 & -0.218 & 1.960 & 0.056 \\
& C2_H & 1.008 & 0.109 & 1.620 & 0.020 \\
\hline \multirow{2}{*}{$\mathrm{C}_{2} \mathrm{H}_{4}$} & C2H4_C & 12.000 & -0.0941 & 2.040 & 0.027 \\
& C2_H & 1.008 & 0.0317 & 1.620 & 0.020 \\
\hline
\end{tabular}


Table S7. Forcefield parameters of bond stretching energy $\left(E_{s t r}\right) . E_{s t r}=71.94 k\left(r-r_{0}\right)^{2}[1-$ $\left.2.25\left(r-r_{0}\right)+\left(\frac{7}{12}\right) 2.25\left(r-r_{0}\right)^{2}\right]$

\begin{tabular}{|c|c|c|}
\hline Bond Pairs & k (kcal mol-1/ $\left./ \AA^{2}\right)$ & $r_{0}(\AA)$ \\
\hline C_1 - O_1 & 5.999 & 1.299 \\
\hline H_1 - O_3 & 3.630 & 0.989 \\
\hline $\mathrm{Zr}-\mathrm{O} \_2$ & 5.809 & 2.192 \\
\hline $\mathrm{Zr}-\mathrm{O} \_1$ & 5.821 & 2.338 \\
\hline O_3 - Zr & 5.500 & 2.276 \\
\hline O_3 - Zr & 5.500 & 2.276 \\
\hline O_2 - Zr & 5.809 & 2.192 \\
\hline C_1 - C_2 & 5.229 & 1.485 \\
\hline C_2 - C_2 & 4.500 & 1.389 \\
\hline C_2 - H_2 & 5.150 & 1.101 \\
\hline C2H4_C - C2H4_C & 7.500 & 1.332 \\
\hline C2H4_C - C2H4_H & 5.150 & 1.101 \\
\hline C2H6_C - C2H6_C & 4.490 & 1.525 \\
\hline C2H6_C - C2H6_H & 4.740 & 1.112 \\
\hline
\end{tabular}


Table S8. Forcefield parameters of bond bending energy $\left(E_{\text {bend }}\right)$. $E_{\text {bend }}=0.021914 k(\theta-$ $\left.\theta_{0}\right)^{2}\left[1-0.014\left(\theta-\theta_{0}\right)+5.6\left(10^{-5}\right)\left(\theta-\theta_{0}\right)^{2}-7.0\left(10^{-7}\right)\left(\theta-\theta_{0}\right)^{3}+2.2\left(10^{-8}\right)\left(\theta-\theta_{0}\right)^{4}\right]$

\begin{tabular}{|c|c|c|}
\hline Angle Type & k (kcal mol ${ }^{-1} /$ radian $\left.^{2}\right)$ & $\theta_{0}$ \\
\hline O_1-C_1-O_1 & 2.867 & 126.299 \\
\hline O_2 - C_2 - O_1 & 2.099 & 84.318 \\
\hline $\mathrm{Zr}-\mathrm{O} \_1-\mathrm{C} \_1$ & 2.099 & 139.820 \\
\hline O_1 - Zr - O_1 & 2.099 & 73.103 \\
\hline $\mathrm{Zr}-\mathrm{O} \_2-\mathrm{Zr}$ & 2.099 & 118.053 \\
\hline $\mathrm{H} \_1-\mathrm{O} \_3-\mathrm{Zr}$ & 2.099 & 116.848 \\
\hline $\mathrm{Zr}-\mathrm{O} \_3-\mathrm{Zr}$ & 2.099 & 103.406 \\
\hline $\mathrm{Zr}-\mathrm{O} \_2-\mathrm{Zr}$ & 2.099 & 118.408 \\
\hline O_1- Zr-O_3 & 2.099 & 89.658 \\
\hline O_2 - Zr - O_3 & 2.099 & 71.110 \\
\hline $\mathrm{Zr}-\mathrm{O} \_3-\mathrm{Zr}$ & 2.099 & 103.406 \\
\hline O_3 - Zr - O_3 & 2.099 & 123.230 \\
\hline O_3 - Zr - O_2 & 2.099 & 71.110 \\
\hline O_2 - Zr - O_2 & 2.099 & 91.479 \\
\hline O_1 - C_1 - C_2 & 1.867 & 117.082 \\
\hline C_1 - C_2 - C_2 & 0.360 & 121.797 \\
\hline C_1 - C_2 - H_2 & 0.360 & 121.797 \\
\hline H_2 - C_2 - C_2 & 0.000 & 119.406 \\
\hline $\mathrm{C} 2 \mathrm{H} 4 \_\mathrm{H}-\mathrm{C} 2 \mathrm{H} 4 \_\mathrm{C}-\mathrm{C} 2 \mathrm{H} 4 \_\mathrm{H}$ & 0.450 & 119.00 \\
\hline C2H4_C - C2H4_C - C2H4_H & 0.490 & 120.00 \\
\hline C2H6_H - C2H6_C - C2H6_H & 0.550 & 107.60 \\
\hline C2H6_C - C2H6_C - C2H6_H & 0.590 & 109.80 \\
\hline
\end{tabular}


Table S9. Forcefield parameters of out of plane bending. Out of plane bending energy have the same form and parameters as in bending energy in Table S7, but with multiplied by ratio 1.

\begin{tabular}{rlll|c}
\hline \multicolumn{3}{c|}{ Out of plane bending type } & l \\
\hline Zr & O_2 & Zr & O_1 & 2.000 \\
O_1 & C_1 & C_2 & O_1 & 0.000 \\
C_2 & C_1 & O_1 & O_1 & 0.000 \\
C_2 & C_2 & H_2 & C_2 & 1.500 \\
\hline
\end{tabular}


Table S10. Forcefield parameters of torsion energy $\left(E_{\text {tor }}\right) . E_{\text {tor }}=0.5 \mathrm{~V}[1+\cos (n \omega-d)]$

\begin{tabular}{c|ccc}
\hline Torsion Type & V(kcal mol $\left.\mathbf{l}^{\mathbf{1}}\right)$ & n & d \\
\hline O_2 - Zr - O_1 - C_1 & 2.064 & 2 & 180 \\
Zr - O_1 - C_1 - O_1 & 2.017 & 2 & 180 \\
O_1 - Zr - O_1 - C_1 & 0.860 & 2 & 180 \\
O_1 - Zr - O_2 - Zr & 1.000 & 2 & 180 \\
C_1 - O_1 - Zr - O_3 & 5.000 & 2 & 180 \\
H_1 - O_3 - Zr - O_1 & 5.000 & 2 & 180 \\
H_1 - O_3 - Zr - O_3 & 5.000 & 2 & 180 \\
H_1 - O_3 - Zr - O_2 & 5.000 & 2 & 180 \\
Zr - O_3 - Zr - O_1 & 5.000 & 2 & 180 \\
Zr - O_3 - Zr - O_3 & 5.000 & 2 & 180 \\
Zr - O_3 - Zr - O_2 & 5.000 & 2 & 180 \\
Zr - O_3 - Zr - O_2 & 5.000 & 2 & 180 \\
Zr - O_2 - Zr - O_3 & 5.000 & 2 & 180 \\
Zr - O_2 - Zr - O_2 & 5.000 & 2 & 180 \\
Zr - O_2 - Zr - O_3 & 5.000 & 2 & 180 \\
Zr - O_1 - C_1 - C_2 & 0.072 & 2 & 180 \\
O_1 - C_1 - C_2 - H_2 & 2.500 & 2 & 180 \\
O_1 - C_1 - C_2 - C_2 & 2.500 & 2 & 180 \\
C_1 - C_2 - C_2 - C_1 & 8.030 & 2 & 180 \\
C_1 - C_2 - C_2 - H_2 & 8.030 & 2 & 180 \\
H_2 - C_2 - C_2 - H_2 & 0.000 & 2 & 180 \\
\hline
\end{tabular}



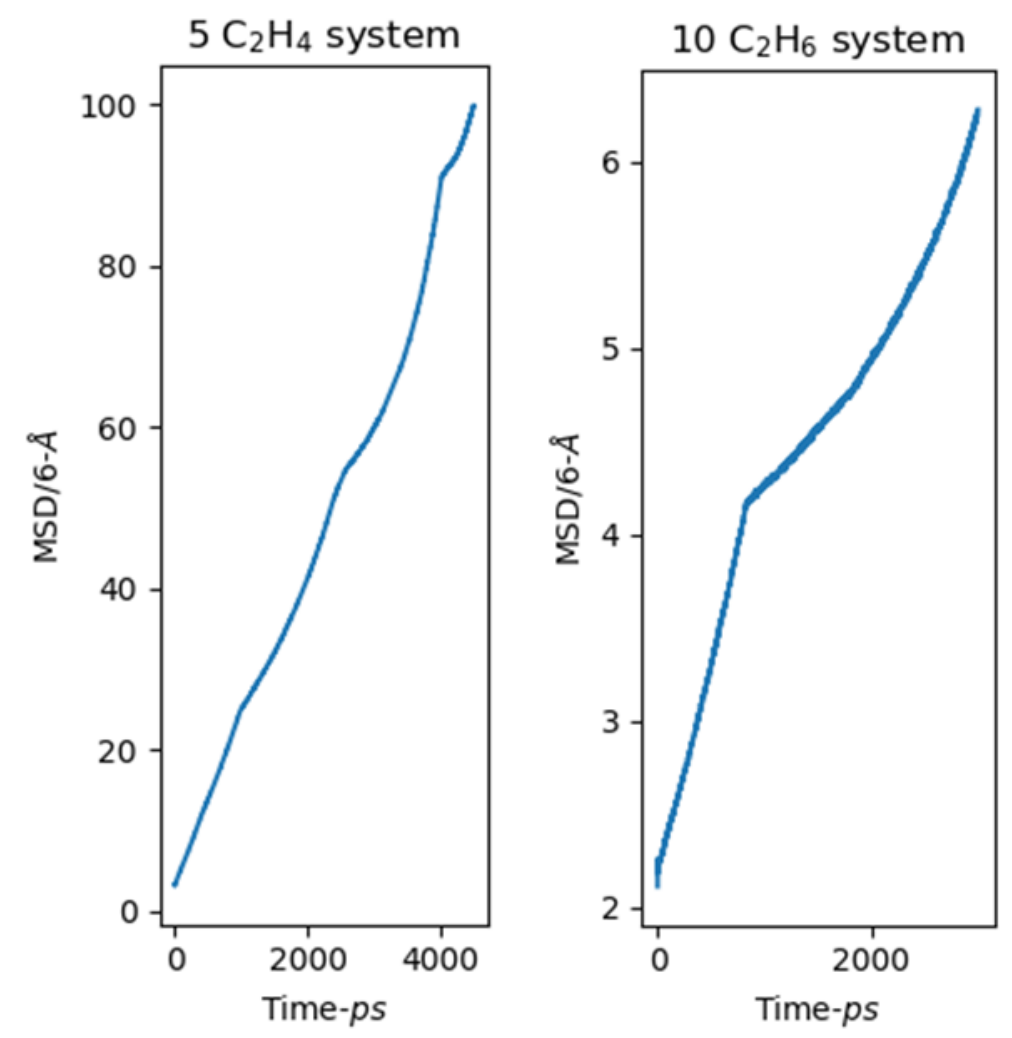

Figure S19. Mean-square-displacement (MSD) as a function of MD simulation time. 
Table S11. The diffusion coefficient calculated from molecular dynamic simulation.

\begin{tabular}{c|c|c|c|c|c}
\hline \multirow{2}{*}{ Pressure } & \multirow{2}{*}{ Sample } & \multicolumn{2}{|c|}{$\begin{array}{c}\text { numbers of molecules per } \\
\text { system }\end{array}$} & \multicolumn{2}{|c}{$\begin{array}{c}\text { Diffusion coefficient }\left(10^{-7}\right. \\
\left.\mathrm{cm}^{2} / \mathrm{s}\right)\end{array}$} \\
\cline { 3 - 6 } & & $\mathrm{C}_{2} \mathrm{H}_{6}$ & $\mathrm{C}_{2} \mathrm{H}_{4}$ & $\mathrm{C}_{2} \mathrm{H}_{6}$ & $\mathrm{C}_{2} \mathrm{H}_{4}$ \\
\hline $0.01 \mathrm{P}_{0}$ & MOF-801 & 10 & 5 & 2.3 & 21.1 \\
\hline
\end{tabular}



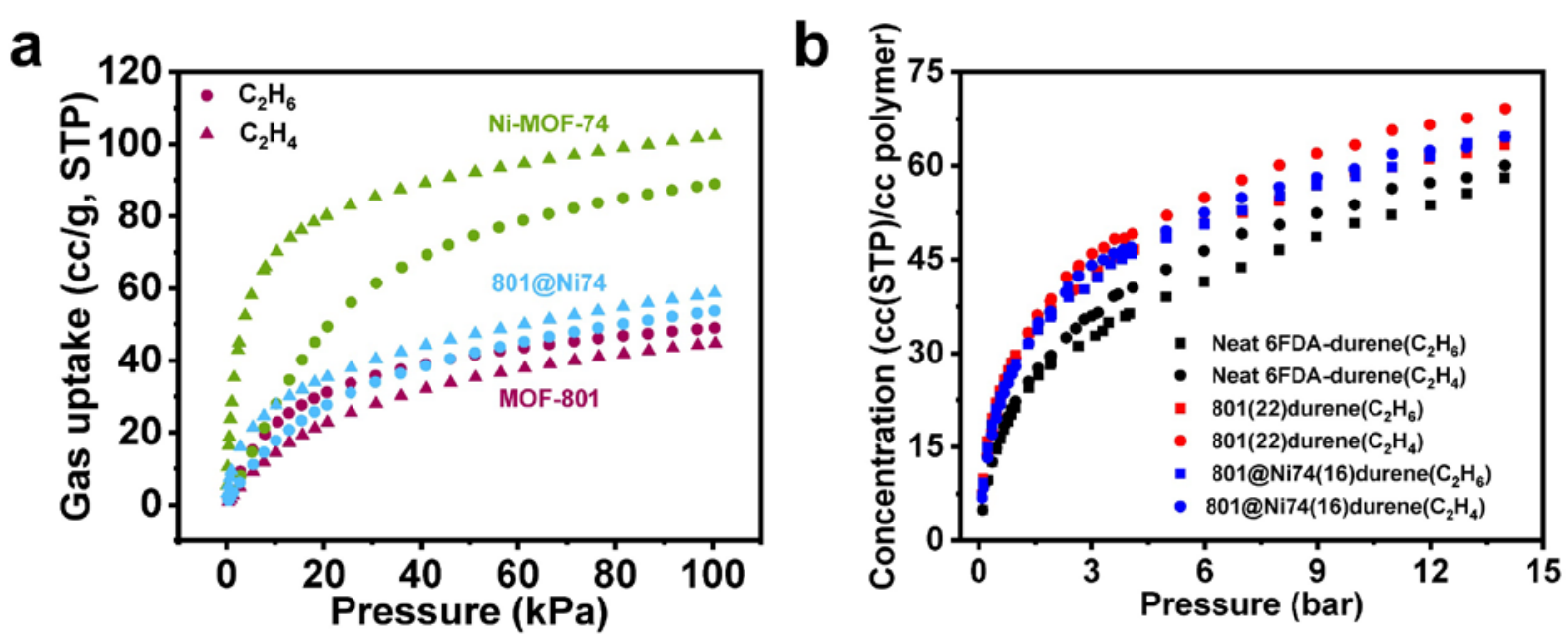

Figure S20. (a) $\mathrm{C}_{2} \mathrm{H}_{6}$ and $\mathrm{C}_{2} \mathrm{H}_{4}$ adsorption isotherms for MOF-801, 801@Ni74 and Ni-MOF-74,

(b) Neat 6FDA-durene, 801@(22)durene and 801@Ni74(16)durene at 308 k. 
Table S12. Comparison of the gas transport properties of MOF-based MMMs and polymeric membranes in literatures with current work.

\begin{tabular}{|c|c|c|c|c|c|c|c|c|c|}
\hline \multirow{2}{*}{ Polymer } & \multirow{2}{*}{ MOF } & \multirow{2}{*}{ Loading (wt\%) } & \multirow{2}{*}{$\begin{array}{c}\mathrm{CO}_{2} \\
\text { (Barrer) }\end{array}$} & \multicolumn{3}{|c|}{$\mathrm{C}_{2} \mathrm{H}_{4}$} & \multicolumn{2}{|c|}{ Operation condition } & \multirow[t]{2}{*}{ Ref. } \\
\hline & & & & & (Barrer) & & $\mathrm{T}\left({ }^{\circ} \mathrm{C}\right)$ & $\Delta \mathbf{P}$ (bar) & \\
\hline 6FAD-6FpDA & - & - & - & - & 1.90 & 4.20 & 35 & 5.07 & 20 \\
\hline 6FDA-1,5-NDA & - & - & - & - & 0.87 & 5.80 & 35 & 5.07 & 20 \\
\hline 6FDA-NDA & - & - & - & - & 1.17 & 6.84 & 35 & 2.03 & 21 \\
\hline 6FDA-NDA/durene (75:25) & - & - & - & - & 4.46 & 5.62 & 35 & 2.03 & 21 \\
\hline 6FDA-NDA/durene (50:50) & - & - & - & - & 9.48 & 4.27 & 35 & 2.03 & 21 \\
\hline 6FDA-NDA/durene (25:75) & - & - & - & - & 36.70 & 3.60 & 35 & 2.03 & 21 \\
\hline 6FDA-durene & - & - & - & - & 76.70 & 2.89 & 35 & 2.03 & 21 \\
\hline 6FDA-TrMPD & - & - & - & - & 58.00 & 2.90 & 50 & 2.03 & 22 \\
\hline BPDA-TeMPD & - & - & - & - & 5.80 & 4.3 & 50 & 2.03 & 22 \\
\hline 6FDA-mPD & - & - & - & - & 0.30 & 3.30 & 35 & 3.85 & 23 \\
\hline 6FDA-IPDA & - & - & - & - & 1.40 & 3.80 & 35 & 3.85 & 23 \\
\hline 6FAD-6FpDA & - & & - & - & 2.10 & 4.40 & 35 & 3.85 & 23 \\
\hline Matrimid ${ }^{\circledR}$ & - & - & - & - & 0.45 & 4.50 & 35 & 3.45 & 24 \\
\hline 6FDA-DAM & - & - & - & - & 64.00 & 3.00 & 35 & 3.45 & 24 \\
\hline 6FDA:BPDA-DAM & - & - & - & - & 46.00 & 3.30 & 35 & 3.45 & 24 \\
\hline 6FDA-DAM & - & - & - & - & 76.00 & 2.90 & 35 & 2.00 & 1 \\
\hline 6FDA-DAM & Co-MOF-74 & 10 & - & - & 141.00 & 3.90 & 35 & 2.00 & 1 \\
\hline
\end{tabular}




\begin{tabular}{|c|c|c|c|c|c|c|c|c|c|}
\hline 6FDA-DAM & Co-MOF-74 & 33 & - & - & 170.00 & 4.90 & 35 & 2.00 & 1 \\
\hline 6FDA-DAM & Ni-MOF-74 & 6 & - & - & 215.00 & 4.00 & 35 & 2.00 & 1 \\
\hline 6FDA-DAM & Ni-MOF-74 & 25 & - & - & 345.00 & 4.60 & 35 & 2.00 & 1 \\
\hline 6FDA-DAM & Mg-MOF-74 & 23 & - & - & 1140.00 & 2.60 & 35 & 2.00 & 1 \\
\hline 6FDA-DAM & Mn-MOF-74 & 13 & - & - & 433.00 & 2.30 & 35 & 2.00 & 1 \\
\hline P84 & $\mathrm{Cu}_{3} \mathrm{BTC}_{2}$ & 10 & - & - & 15.80 & 5.20 & 35 & 5.00 & 25 \\
\hline P84 & $\mathrm{Cu}_{3} \mathrm{BTC}_{2}$ & 20 & - & - & 18.30 & 7.10 & 35 & 5.00 & 25 \\
\hline 6FDA-DAM & ZIF-8 & 16.4 & & & 71.33 & 3.19 & 35 & 3.45 & 24 \\
\hline 6FDA-DAM & ZIF-8 & 48 & & & 251.80 & 2.99 & 35 & 3.45 & 24 \\
\hline ODPA-DAM & - & - & 64.87 & 30.88 & - & - & 35 & 3.1 & 26 \\
\hline ODPA-DAM & UiO-66- $\mathrm{NH}_{2}$ & 5 & 78.78 & 26.56 & - & - & 35 & 3.1 & 26 \\
\hline ODPA-DAM & UiO-66- $\mathrm{NH}_{2}$ & 9 & 102.67 & 23.01 & - & - & 35 & 3.1 & 26 \\
\hline ODPA-DAM & UiO-66- $\mathrm{NH}_{2}$ & 17 & 110.95 & 24.09 & - & - & 35 & 3.1 & 26 \\
\hline ODPA-DAM & UiO-66-NH & 27 & 229.25 & 9.01 & - & - & 35 & 3.1 & 26 \\
\hline
\end{tabular}




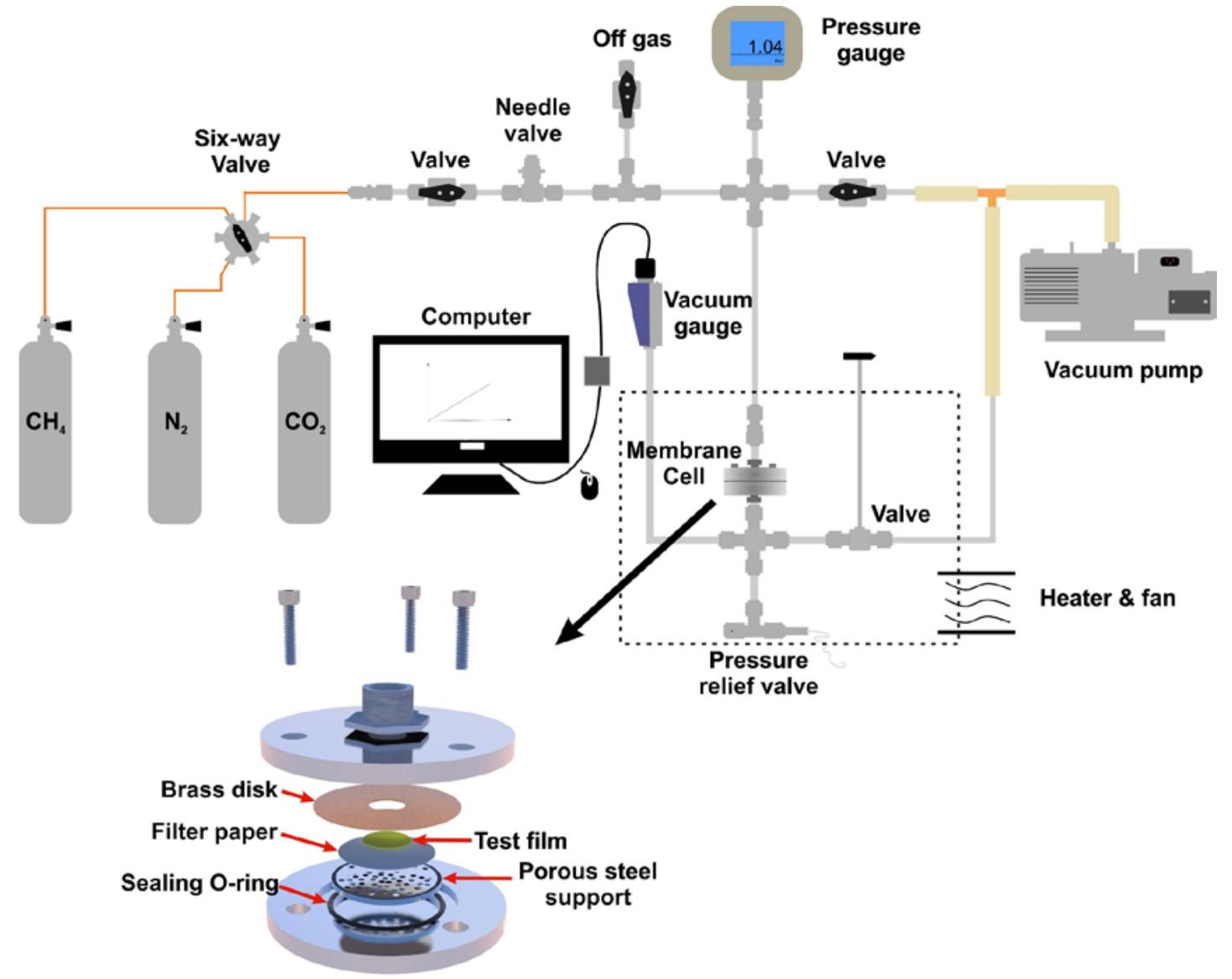

Figure S21. Schematic diagram of home built single gas permeation setup. 


\section{Section S5. Reference}

(1) Bachman, J. E.; Smith, Z. P.; Li, T.; Xu, T.; Long, J. R., Enhanced ethylene separation and plasticization resistance in polymer membranes incorporating metal-organic framework nanocrystals. Nat. Mater. 2016, 15 (8), 845 849.

(2) Furukawa, H.; Gandara, F.; Zhang, Y.-B.; Jiang, J.; Queen, W. L.; Hudson, M. R.; Yaghi, O. M., Water adsorption in porous metal-organic frameworks and related materials. J. Am. Chem. Soc. 2014, 136 (11), 4369-4381.

(3) Do, D. D., Adsorption analysis: equilibria and kinetics. Imperial college press London: 1998; Vol. 2.

(4) Turcani, L.; Berardo, E.; Jelfs, K. E., stk: A python toolkit for supramolecular assembly. J. Comput. Chem. 2018, 39 (23), 1931-1942.

(5) Halgren, T. A., MMFF VI. MMFF94s option for energy minimization studies. J. Comput. Chem. 1999, 20 (7), 720-729.

(6) Martínez, L.; Andrade, R.; Birgin, E. G.; Martínez, J. M., PACKMOL: a package for building initial configurations for molecular dynamics simulations. J. Comput. Chem. 2009, 30 (13), 2157-2164.

(7) Dauber-Osguthorpe, P.; Roberts, V. A.; Osguthorpe, D. J.; Wolff, J.; Genest, M.; Hagler, A. T., Structure and energetics of ligand binding to proteins: Escherichia coli dihydrofolate reductase - trimethoprim, a drug-receptor system. Proteins: Struct., Funct., Bioinf. 1988, 4 (1), 31-47.

(8) Rappe, A. K.; Goddard III, W. A., Charge equilibration for molecular dynamics simulations. J. Phys. Chem. 1991, 95 (8), 3358-3363.

(9) Plimpton, S., Fast parallel algorithms for short-range molecular dynamics. J. Comput. Phys. 1995, 117 (1), 1-19.

(10) Dubbeldam, D.; Calero, S.; Ellis, D. E.; Snurr, R. Q., RASPA: molecular simulation software for adsorption and diffusion in flexible nanoporous materials. Mol. Simul. 2016, 42 (2), 81-101.

(11) Rappé, A. K.; Casewit, C. J.; Colwell, K.; Goddard III, W. A.; Skiff, W. M., UFF, a full periodic table force field for molecular mechanics and molecular dynamics simulations. J. Am. Chem. Soc. 1992, 114 (25), 10024-10035.

(12) Potoff, J. J.; Siepmann, J. I., Vapor-liquid equilibria of mixtures containing alkanes, carbon dioxide, and nitrogen. AIChE J. 2001, 47 (7), 1676-1682.

(13) Wick, C. D.; Martin, M. G.; Siepmann, J. I., Transferable potentials for phase equilibria. 4. United-atom description of linear and branched alkenes and alkylbenzenes. J. Phys. Chem. B 2000, 104 (33), 8008-8016.

(14) Bristow, J. K.; Tiana, D.; Walsh, A., Transferable force field for metal-organic frameworks from first-principles: BTW-FF. J. Chem. Theory Comput. 2014, 10 (10), 4644-4652.

(15) Plimpton, S. Fast parallel algorithms for short-range molecular dynamics; Sandia National Labs., Albuquerque, NM (United States): 1993.

(16) Allinger, N. L.; Yuh, Y. H.; Lii, J. H., Molecular mechanics. The MM3 force field for hydrocarbons. 1. J. Am. Chem. Soc. 1989, 111 (23), 8551-8566.

(17) Liu, G.; Labreche, Y.; Chernikova, V.; Shekhah, O.; Zhang, C.; Belmabkhout, Y.; Eddaoudi, M.; Koros, W. J., Zeolite-like MOF nanocrystals incorporated 6FDA-polyimide mixed-matrix membranes for $\mathrm{CO}_{2} / \mathrm{CH}_{4}$ separation. $J$. Membr. Sci. 2018, 565, 186-193.

(18) Koros, W. J.; Zhang, C., Materials for next-generation molecularly selective synthetic membranes. Nat. Mater. 2017, 16 (3), 289-297.

(19) Scherrer, P., Bestimmung der inneren Struktur und der Größe von Kolloidteilchen mittels Röntgenstrahlen. In Kolloidchemie Ein Lehrbuch, Springer: 1912; pp 387-409.

(20) Chan, S. S.; Wang, R.; Chung, T.-S.; Liu, Y., C2 and C3 hydrocarbon separations in poly (1, 5-naphthalene-2, $2^{\prime}$-bis (3, 4-phthalic) hexafluoropropane) diimide (6FDA-1, 5-NDA) dense membranes. J. Membr. Sci. 2002, 210 (1), 55-64.

(21) Chan, S. S.; Chung, T.-S.; Liu, Y.; Wang, R., Gas and hydrocarbon (C2 and C3) transport properties of copolyimides synthesized from 6FDA and 1, 5-NDA (naphthalene)/Durene diamines. J. Membr. Sci. 2003, 218 (1-2), 235-245.

(22) Tanaka, K.; Taguchi, A.; Hao, J.; Kita, H.; Okamoto, K., Permeation and separation properties of polyimide membranes to olefins and paraffins. J. Membr. Sci. 1996, 121 (2), 197-207.

(23) Staudt-Bickel, C.; Koros, W. J., Olefin/paraffin gas separations with 6FDA-based polyimide membranes. $J$. Membr. Sci. 2000, 170 (2), 205-214.

(24) Rungta, M.; Zhang, C.; Koros, W. J.; Xu, L., Membrane-based ethylene/ethane separation: The upper bound and beyond. AIChE J. 2013, 59 (9), 3475-3489. 
(25) Ploegmakers, J.; Japip, S.; Nijmeijer, K., Mixed matrix membranes containing MOFs for ethylene/ethane separation-Part B: effect of Cu3BTC2 on membrane transport properties. J. Membr. Sci. 2013, 428, 331-340.

(26) Wang, H.; He, S.; Qin, X.; Li, C.; Li, T., Interfacial engineering in metal-organic framework-based mixed matrix membranes using covalently grafted polyimide brushes. J. Am. Chem. Soc. 2018, 140 (49), 17203-17210. 